\title{
REVIEW \\ Interplay between epigenetics and metabolism in oncogenesis: mechanisms and therapeutic approaches
}

\author{
CC Wong ${ }^{1}, Y$ Qian ${ }^{2,3}$ and $J \mathrm{Yu}^{1}$
}

Epigenetic and metabolic alterations in cancer cells are highly intertwined. Oncogene-driven metabolic rewiring modifies the epigenetic landscape via modulating the activities of DNA and histone modification enzymes at the metabolite level. Conversely, epigenetic mechanisms regulate the expression of metabolic genes, thereby altering the metabolome. Epigenetic-metabolomic interplay has a critical role in tumourigenesis by coordinately sustaining cell proliferation, metastasis and pluripotency.

Understanding the link between epigenetics and metabolism could unravel novel molecular targets, whose intervention may lead to improvements in cancer treatment. In this review, we summarized the recent discoveries linking epigenetics and metabolism and their underlying roles in tumorigenesis; and highlighted the promising molecular targets, with an update on the development of small molecule or biologic inhibitors against these abnormalities in cancer.

Oncogene (2017) 36, 3359-3374; doi:10.1038/onc.2016.485; published online 16 January 2017

\section{INTRODUCTION}

It has been appreciated since the early days of cancer research that the metabolic profiles of tumor cells differ significantly from normal cells. Cancer cells have high metabolic demands and they utilize nutrients with an altered metabolic program to support their high proliferative rates and adapt to the hostile tumor microenvironment. Cancer cells could metabolize glucose via glycolysis to generate lactate, instead of oxidative phosphorylation (OXPHOS), even in the presence of normal oxygen levels. ${ }^{1-3}$ Although the process is less efficient compared with OXPHOS, glycolysis has a much higher turnover and provides intermediates for macromolecular biosynthesis and redox homeostasis. Apart from metabolizing glucose, cancer cells are addicted to glutamine. By means of a process known as glutaminolysis, cancer cells could divert a major fraction of glutamine to replenish the tricarboxylic acid (TCA) cycle. ${ }^{4-6}$ Hence, glutaminolysis supplies biosynthetic precursors for nucleotides, proteins and glutathione biosynthesis in tumorigenesis. ${ }^{7,8}$

Oncogenic pathways have well-established roles in metabolic rewiring in human cancers. For instance, mutations in KRAS, PIK3CA, PTEN or AKT have been shown to hyperactivate mTORAKT pathway, which stimulates glycolysis via upregulation of glucose transporter 1 (GLUT1), ${ }^{9-11}$ and the phosphorylation of rate-limiting glycolytic enzymes, including hexokinases (HKs) and 6-phosphofructo-2-kinase/fructose-2,6-bisphosphatases (PFK2/ FBPase 2). ${ }^{12,13}$ The oncogenic transcription factor MYC mediates the transcription of almost all the genes involved in glycolysis and glutaminolysis, ${ }^{6,14}$ and it promotes shuttling of glycolytic intermediates to pentose phosphate pathway to generate large quantities of reduced nicotinamide adenine dinucleotide phosphate (NADPH) and promote macromolecule biosynthesis via the induction of pyruvate kinase isozymes M2 (PKM2). ${ }^{15}$ Numerous metabolic genes have also been identified as driver genes mutated in some cancers, such as isocitrate dehydrogenase 1 and $2(\mathrm{IDH} 1 / 2)$ in gliomas ${ }^{16}$ and acute myeloid leukemia (AML), ${ }^{17}$ succinate dehydrogenase (SDH) in paragangliomas ${ }^{18}$ and fumarate hydratase $(\mathrm{FH})$ in hereditary leiomyomatosis and renal cell cancer (HLRCC). ${ }^{19}$ Metabolic rewiring of cancer cells is considered as one of 10 hallmarks of cancer. ${ }^{20}$

Metabolic rewiring in cancer has profound effects on regulation of gene expression. Although metabolite profiles might have little impact on the genetic level, it appears that they have a fundamental role in epigenetic regulation of gene expression. Epigenetics refers to heritable changes in gene expression, which are not a consequence of alterations in the DNA sequence. Epigenetic regulation of gene expression can be highly plastic and responsive to various environmental clues. ${ }^{21-23}$ Epigenetics, which principally involved the chemical modification of DNA and histones, represents an innate mechanism that links nutritional status to gene expression. As such, metabolic rewiring could hijack the epigenome machinery in cancer cells to transmit a mitogenic gene expression profile. ${ }^{24-26}$ Reciprocally, epigenetic deregulation in cancer mediates, at least in part, to the altered expression of genes involved in cellular metabolism.

A four-way crosstalk exists between epigenetics and metabolism in cancer (Figure 1). Metabolic rewiring could affect the availability of cofactors required for epigenetic modification enzymes (1) and generate oncometabolites that act as agonists and/or antagonists for epigenetic modification enzymes (2), thus impacting the epigenetic landscape (Figure 2). On the other hand, epigenetic dysfunction modifies metabolism by directly affecting the expression of metabolic enzymes (3) and altering the signal transduction cascades involved in the control of cell metabolism (4) (Figure 3). In this review, we provide a summary of molecular

\footnotetext{
${ }^{1}$ Department of Medicine and Therapeutics, State Key Laboratory of Digestive Disease, Li Ka Shing Institute of Health Sciences, Shenzhen Research Institute, The Chinese University of Hong Kong, Hong Kong, China; ${ }^{2}$ Department of Gastroenterology, Sir Run Run Shaw Hospital, School of Medicine, Zhejiang University, Hangzhou, China and

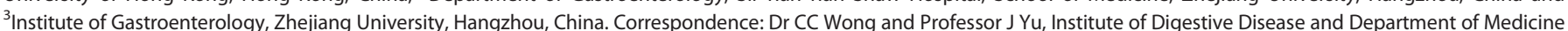
and Therapeutics, State Key Laboratory of Digestive Disease, Li Ka Shing Institute of Health Sciences, Shenzhen Research Institute, Chinese University of Hong Kong, Rm 707A, 7/F., Li Ka Shing Medical Sciences Building, Prince of Wales Hospital, 30-32 Ngan Shing Street, Hong Kong, China.
}

E-mail: chichun.wong@cuhk.edu.hk or junyu@cuhk.edu.hk

Received 20 September 2016; revised 7 November 2016; accepted 7 November 2016; published online 16 January 2017 


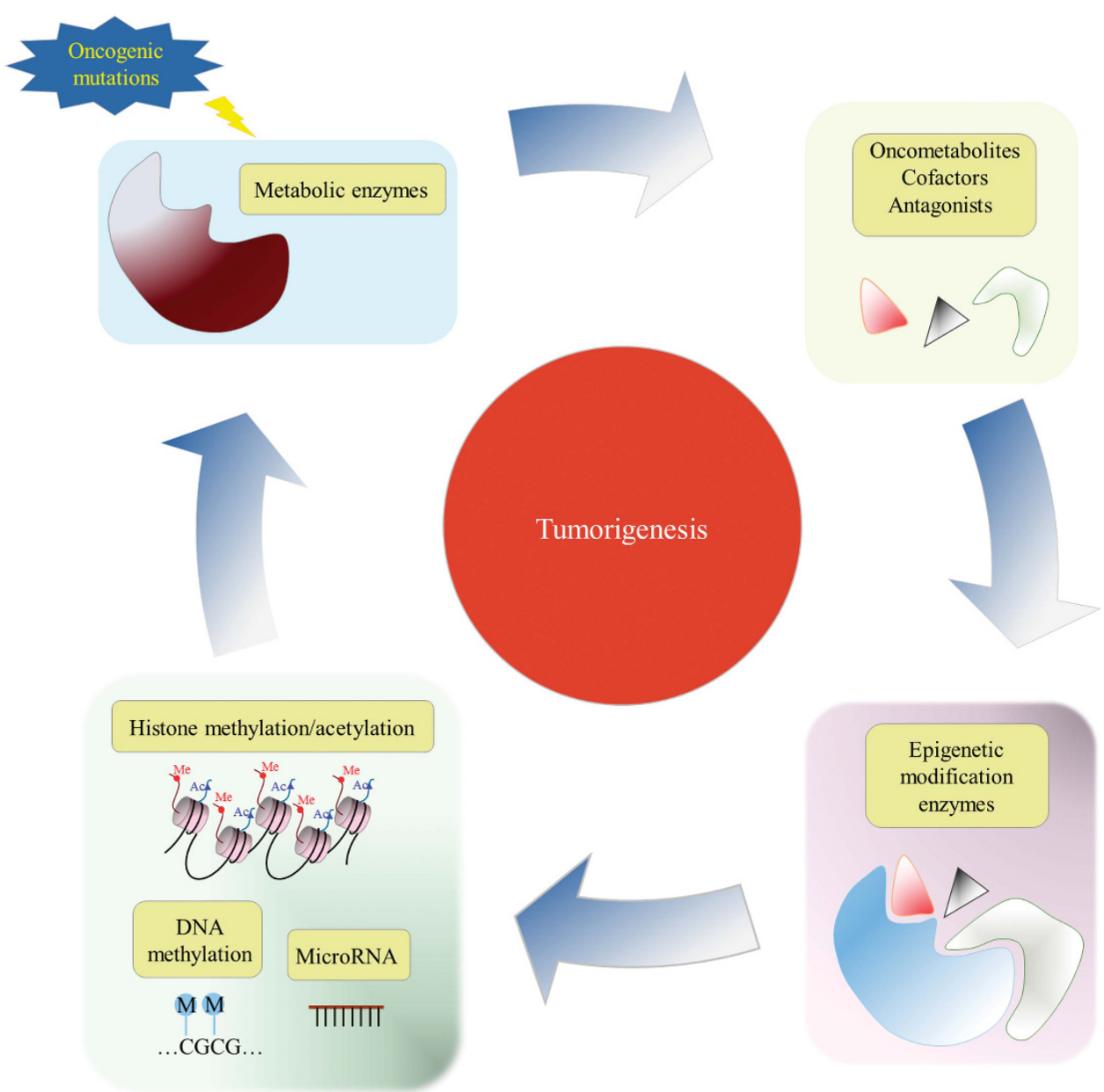

Figure 1. Crosstalks between epigenetics and metabolism in cancer development.

mechanisms linking epigenetics and metabolism; and their underlying roles in tumorigenesis; highlight the potential molecular targets whose inhibition may abrogate these crosstalks and suppress tumorigenesis; and an outline of therapeutics against these potential drug targets.

\section{EFFECT OF METABOLIC REWIRING ON EPIGENETIC MODIFICATION ENZYMES}

SAM/SAH ratio regulates DNA and histone methylation

DNA methylation is the most extensively studied epigenetic alteration in cancers. Promoter DNA methylation at CpG sites represses gene expression by impeding access to transcription factors and inhibition of RNA polymerase $1 .^{27-29}$ In cancer, aberrant DNA methylation is typically observed in the promoter regions of various tumor suppressor genes and microRNAs, ${ }^{30-38}$ leading to their transcriptional silence. DNA methylation is mediated by DNA methyltransferases, which catalyze the covalent addition of a methyl group to cytosine to form 5-methylcytosine $(5 \mathrm{mC})$. All DNMT isoforms, DNMT1, DNMT3A and DNMT3B, are overexpressed in cancers. $^{39}$ Methylation markers on lysine residues in histone proteins also have a key role in regulating chromatin structure and gene transcription. Multiple lysine residues (H3K4, H3K9, H3K27, H3K36, H3K79 and so on) may be mono-, di- or tri-methylated, giving rise to a very complex histone methylation code. ${ }^{40}$ Histone methyltransferases (HMTs) that mediate histone-lysine methylation consist of two enzyme families, SET-domain (SETD) containing and Dot1-like (DOT1L) proteins. $^{41}$

DNMTs and HMTs utilize a common activated methyl donor for methyltransferase activity: S-adenosylmethionine (SAM). SAM is a product of one-carbon metabolism cycle and is synthesized by methionine adenosyltransferase (MAT) using methionine and ATP as substrates. Donation of methyl group from SAM invariably releases $S$-adenosyl-homocysteine $(\mathrm{SAH})$ as the product and the latter is a potent inhibitor of methyltransferase such as DNMTs and HMTs. Hence, the SAM/SAH ratio dictates methyltransferase activity in vivo. SAH is physiologically maintained at low levels via hydrolysis to homocysteine, which can be recycled to methionine via the transfer of a methyl group from 5-methyltetrahydrofolate. Alternatively, homocysteine can be catabolized to give amino acids, glutathione and inorganic sulfate. Changes in SAM/SAH ratio and one-carbon cycle will thus modulate the activity of DNMTs and HMTs. ${ }^{42}$

An excess supply of SAM might contribute to DNA hypermethylation at CpG sites and inappropriate gene silencing. Glycine $\mathrm{N}$-methyltransferase (GNMT) deficiency is a rare genetic condition leading to SAM over-production. ${ }^{43}$ The genetic knockout of Gnmt in mice increased hepatic SAM by over 40 -fold. ${ }^{43}$ Moreover, Gnmt knockout mice demonstrated promoter methylation of tumor suppressor genes such as RASSF1 and SOCS2, which led to their transcriptional silencing. ${ }^{44}$ As a consequence, Gnmt knockout was associated with activation of oncogenic pathways and an increased incidence of hepatocellular carcinoma. ${ }^{44}$ Cancer cells have also been shown to boost SAM availability via promoting 


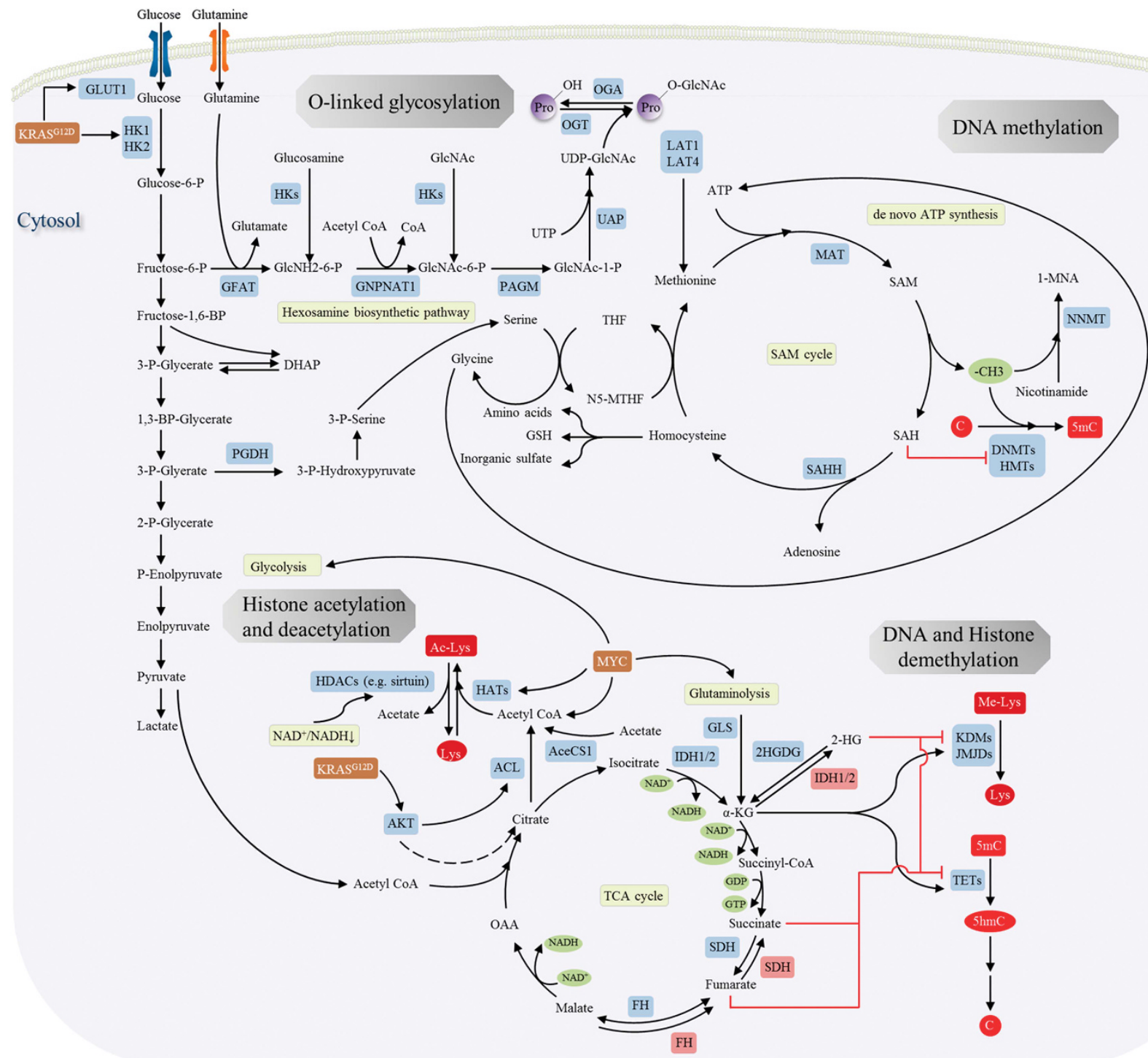

Figure 2. Effect of the tumor metabolome on the epigenetic processes such as histone acetylation, DNA methylation, DNA/histone demethylation, $\mathrm{N}$-linked glycosylation in human cancers. An altered epigenetic regulation in turn contributes to deregulation of gene expression.

one-carbon metabolism. Cancer cells could directly increase the uptake of methionine through the overexpression of amino-acid transporters LAT1 and LAT4 (SLC7A5/SLC43A2). ${ }^{45,46}$ Alternatively, overexpression of 3-phosphoglycerate dehydrogenase (PGDH) diverts glycolysis intermediates to the serine-glycine biosynthesis pathway. ${ }^{47,48}$ Serine participates in one-carbon metabolism through donation of its side chain to tetrahydrofolate to drive the folate cycle, which in turn recycles methionine from homocysteine. Serine also supports SAM synthesis from methionine through de novo ATP synthesis, a major contributor to the functional ATP pool in cancer cells. ${ }^{49}$

Alterations in SAM/SAH ratio also profoundly affect aberrant histone methylation in cancers. Nicotinamide $\mathrm{N}$-methyl-transferase (NNMT) catalyzes the conversion of nicotinamide to 1-methylnicotinamide (1-MNA) using SAM as methyl donor. NNMT is overexpressed in a variety of cancers, including lung, liver, kidney bladder and colon cancers and exerts an oncogenic effect. ${ }^{50-53}$ Recently, NNMT expression was found to be upregulated in human embryonic stem cells, and NNMT is indispensable for the maintenance for pluripotency. NNMT serves as a sink for SAM, severely depleting cellular SAM pool, resulting in $>50 \%$ reduction in the SAM/SAH ratio and making SAM unavailable for
HMTs. ${ }^{54}$ As a consequence, cell lines overexpressing NNMT showed a substantial decrease in histone methylation marks at H3K4, H3K9, H3K27 and H4K20. Altered histone methylation further regulated key signaling pathways associated with acquisition of a more aggressive/pluripotent phenotype. Conversely, knockdown of NNMT increased histone methylation. However, DNA methylation was not affected by NNMT overexpression or knockdown. The apparent discrepancy between DNA and histone methylation may arise from varying $K_{\mathrm{m}}$ values of DNMTs and HMTs for SAM. HMTs possess high $K_{\mathrm{m}}$ values for SAM, thereby conferring a higher sensitivity to changes in SAM levels.

SAM, as an activated methyl donor for DNMTs and HMTs, has a major impact on the epigenomic landscape. Given the myriad of processes that are affected by histone and DNA methylation, and the diversity of the downstream signaling pathways involved, deregulation of SAM levels in cancers likely has a contextdependent effect, and much remains to be explored.

TCA cycle metabolites modulate DNA and histone demethylation The dynamics of DNA and histone methylation is additionally regulated by the activity of DNA and histone demethylases, 


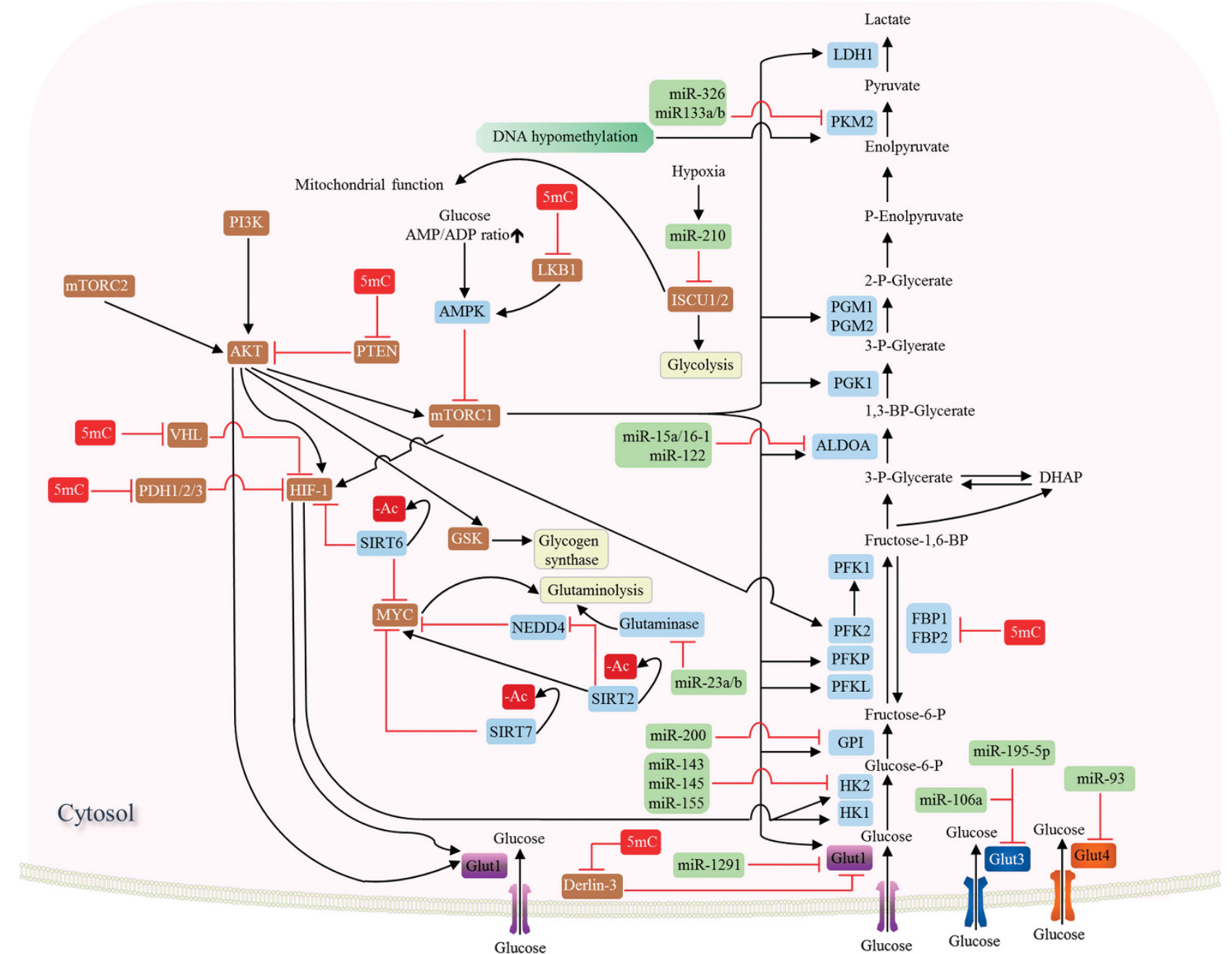

Figure 3. Effect of DNA hypermethylation (5mC), histone deacetylation (-Ac) and microRNA (miRs) on the expression of metabolic enzymes involved in glycolysis and glutaminolysis in cancer.

respectively. Methylated cytosine residues are demethylated in two sequential steps, involving oxidation of 5-methyl-cytosine (5-mC) to 5-hydroxymethyl-cytosine $(5-\mathrm{hmC})$, catalyzed by the 10-11 translocation (TETs) family of proteins, ${ }^{55-57}$ followed by reversion to cytosine through oxidation and base excision repair by thymine DNA glycosylase (TDG). ${ }^{58}$ TETs are putative tumor suppressors. Frequent inactivating TET2 mutations have been detected in myeloid lineage malignancies ${ }^{59}$ and downregulation of TETs have been observed in several human cancers. ${ }^{60-62}$ Therefore, hyperactive methylation and deactivated demethylation machinery work in conjunction to induce promoter DNA hypermethylation in cancers. Demethylation of histone lysine marks is mediated by flavin-dependent Histone Lysine Demethylases that consist of lysine-specific protein demethylases (KDM1) family and jumonji C-domain-containing (JMJD) enzymes. The role of histone demethylases in cancer is less clear-cut. ${ }^{63}$ In some cases, histone demethylases are downregulated by gene mutations or deletions in cancers, but in others they can be amplified, such as JMJD2 $\mathrm{C}^{64}$ and lysine-specific protein demethylases LSD1. ${ }^{65}$ TETs and JMJDs both belong to a-ketoglutarate (a-KG)dependent dioxygenases that requires $a-K G$ as a cofactor and is competitively inhibited TCA cycle intermediates such as succinate and fumarate. ${ }^{66}$ Cancer cells with mutations in metabolic genes may gain the ability to accumulate or synthesize metabolites, such as 2-hydroxylglutarate (2-HG), succinate and fumarate. 2-hydroxyglutarate. Mutations in the metabolic enzymes isocitrate dehydrogenase (IDH) isoforms IDH1 and IDH2 are common in gliomas, ${ }^{16,67} \mathrm{AML}^{17,68,69}$ and angioimmunoblastic T-cell lymphoma. ${ }^{70} \mathrm{IDH} 1 / 2$ are Nicotinamide Adenine Dinucleotide Phosphate (NADP) ${ }^{+}$-dependent metabolic enzymes that participate in the TCA cycle, catalyzing a two-step reaction for oxidative decarboxylation of isocitrate to $\mathrm{a}-\mathrm{KG} .^{71}$ Mutations in IDH1/2 occur at substrate binding sites (IDH1: R132; IDH2: R140/172). Mutant IDH1/2 possess oncogenic properties, and their ectopic expression enhanced cancer cell proliferation, colony formation and inhibits cellular differentiation in vitro. ${ }^{69,72,73}$ These mutations abrogate the ability of IDH1/2 to synthesize isocitrate from a-KG but are accompanied by the gain-of-function conversion of a-KG to 2$\mathrm{HG}^{72} 2-\mathrm{HG}$ is pivotal to the functional effect of mutant IDH1/2. This oncometabolite accumulates to very high levels ( 5 to $35 \mathrm{~mm}$ ) in mutant IDH1/2 tumors. 2-HG is structurally similar to a-KG and it acts as a competitive antagonist. Thus, 2-HG inhibits activity of a-KG dependent dioxygenases, such as TETs and JMJDs, which have broad implications for the regulation of epigenome. ${ }^{74}$ Apart from tumors with mutant IDH1/2, increased $2-\mathrm{HG}$ have also been reported in breast cancer ${ }^{75}$ and renal cancer (L-enantiomer), ${ }^{76}$ which is associated with activation of MYC and L-2-hydroxyglutarate dehydrogenase (L2HGDG) deficiency, respectively. The former promotes glutaminolysis and 2-HG production via 
wild type IDH2; while inactivation of L2HGDG prevents conversion of $2-\mathrm{HG}$ back to a-KG. ${ }^{77}$

TET1/2-mediated conversion of $5 \mathrm{mC}$ to $5 \mathrm{hmC}$ is a relevant target of $2-\mathrm{HG} .{ }^{17,74}$ In vitro enzymatic assays with TET1/2 revealed that 2 -HG behaves as a competitive inhibitor. ${ }^{78,79}$ Its inhibitory effect was especially pronounced for TET2, with $33 \%$ and $83 \%$ at 10 and $50 \mathrm{~mm}$, respectively. Either introduction of mutant IDH1/2 or 2-HG abrogated TET1/2-mediated formation of 5 -hmC in human cell lines. Moreover, ectopic expression of mutant $\mathrm{IDH} 1^{\mathrm{R} 132 \mathrm{H}}$ into primary human astrocytes is sufficient to produce a CpG island methylator phenotype (CIMP) by inducing hypermethylation in a large number of genes. In human patients, IDH1/2 mutations in glioma or AML define distinct patient subgroups associated with CIMP. ${ }^{80,81}$ DNA hypermethylation induced by $2-\mathrm{HG}$ is reversible, and therefore represents a viable therapeutic target in IDH1/2-mutant cancers. ${ }^{17}$

2-HG levels in IDH1/2 mutant tumors also have implications for histone demethylase activity. ${ }^{78}$ 2-HG strongly inhibited several histone demethylases (JMJD2A/KDM4A, JMJD2C/KDM4C and JHDM1A/KDM2A) as compared to other dioxygenases. Other studies additionally identified 2-HG as a histone demethylases KDM7A inhibitor ${ }^{73,79}$ by binding to catalytic core and competing with a-KG. In U-87MG (human glioma cells), 2-HG or overexpression of mutant IDH1 increased H3K9, H3K27 and H3K79 dimethylation and H3K4 trimethylation. ${ }^{79}$ Knockin of $\mathrm{IDH} 1^{\mathrm{R} 132 \mathrm{H}}$ in haematopoietic cells was associated with increased dimethylation of H3K79 and trimethylation of H3K4, H3K9, H3K27 and H3K36. ${ }^{74}$ Alterations in these methylated histone marks, in particular H3K9 trimethylation, were found to promote pluripotency and inhibit differentiation. ${ }^{73}$ Human primary glioma with mutant IDH1 had elevated H3K79 dimethylation levels compared with those with wild type; ${ }^{73}$ oligodendroglioma patients with mutations in IDH1 also had higher H3K9me3 compared with those with wild-type IDH $1 / 2 .^{82}$ Given a large number of JMJDs enzymes and their diverse substrate specificities, more studies are required to unravel the full spectrum of histone methylation induced by $2-\mathrm{HG}$ and its biological significance.

Succinate and fumarate. Inactivating mutations in TCA cycle enzymes fumarate hydratase $(\mathrm{FH})$ and succinate dehydrogenase $(\mathrm{SDH})$ are driver mutations in a subset of human cancers and they mediate epigenetic reprogramming. ${ }^{83} \mathrm{SDH}$ mutations are present in gastrointestinal stromal tumors (GISTs), renal cell carcinoma, paraganglioma and pheochromocytoma. ${ }^{84-88} \mathrm{SDH}$ consists four subunits (SDHA, SDHB, SDHC and SDHD) and it catalyzes oxidation of succinate to fumarate. Mutations in any of the four subunits can inactivate the SDH complex, leading marked accumulation of succinate. Mutations in $\mathrm{FH}$ have been detected in HLRCC. ${ }^{19}$ Mitochondrial $\mathrm{FH}$ mediates the reversible conversion between fumarate and malate, and the loss-of-function mutation of $\mathrm{FH}$ resulted in high levels of fumarate.

Recent data have shed new light on the mechanisms of the tumor suppressor effect of $\mathrm{FH}$ and $\mathrm{SDH}$. Both succinate and fumarate behave as a-KG competitive antagonists for inhibiting TETs and JMJDs. Both of these metabolites inhibited TETscatalyzed hydroxylation of $5 \mathrm{mC}$ and the activity of histone demethylases KDM2A and KDM4A. ${ }^{66}$ Ectopic expression of $\mathrm{FH}$ and SDH mutants recapitulated the effect of fumarate and succinate. Furthermore, mouse chromaffin cells with genetic knockout of Sdhb exhibited a methylator phenotype, with an increased 5-mC/5-hmC ratio and enhanced histone methylation at H3K9, H3K27, and H3K27.89 Epigenetic dysregulation in Sdhb knockout cells triggered a transcriptional program that downregulated genes associated with the suppression of metastasis, leading to increased cell invasiveness. Consistent with in vitro data, a deregulated epigenomic landscape is frequently observed in $\mathrm{FH}$ or $\mathrm{SDH}$ mutant tumors. Gastrointestinal stoma tumors (GISTs) harboring mutant SDH have genomic DNA methylation an order of a magnitude greater than c-Kit-mutated GISTs. ${ }^{90}$ Genomic hypermethylation was also observed in patients with SDH-mutant hereditary paraganglioma and pheochromocytoma. Moreover, paraganglioma patients with SDH or FH-deficiency associated DNA CIMP had a much worse prognosis compared with other molecular subtypes, indicating that epigenetic dysregulation in $\mathrm{SDH}$ or $\mathrm{FH}$-mutant patients contributes to tumor development and progression. ${ }^{89}$ Thus, genetic mutations in $\mathrm{FH}$ and SDH can lead to accumulation of fumarate and succinate, respectively, which drives tumorigenesis via epigenetic deregulation.

\section{Acetyl-CoA and NAD ${ }^{+}$influence histone acetylation}

Histone acetylation involves the addition of an acetyl group to lysine residues. Histone acetylation is dynamically regulated by opposing actions of histone acetyltransferases (HATs) and histone deacetylases (HDACs) that catalyze the addition and removal of the acetyl group, respectively. HATs are divided into GCN5/PCAF, p300/CBP and MYST (MOZ, Ybf2/Sas3, Sas2, Tip60) families, whereas HDACs are classified into four groups: the zincdependent class I, II and IV and NAD ${ }^{+}$-dependent class III HDACs (also known as sirtuins). Histone acetylation decreases the electronic interaction between histones and negatively charged DNA, which is associated with a more open chromatin structure and active gene transcription ${ }^{91}$. HDAC-mediated histone deactylation has well-recognized roles in cancers via transcriptional repression of tumor suppressor genes. ${ }^{92,93}$ While some HATs are also putative tumor suppressors and inactivating mutations in p300/CBP have been identified in breast, colorectal and gastric cancers, ${ }^{94,95}$ several fusion genes that involve HATs, such as MLL-CBP $^{96}$ and MOZ-TIF2 ${ }^{97}$ behaves as oncogenic factors in hematological malignancies.

Acetyl-CoA. Acetyl-CoA is an important molecule in intermediary metabolism. It fuels the TCA cycle and it is at the crossroads of glycolysis, glutaminolysis and $\beta$-oxidation of fatty acids in mitochondria. Cytosolic and nuclear acetyl-CoA levels are maintained by two metabolic pathways, its direct synthesis from acetate and CoA by acetyl-CoA synthetase short-chain family 1 (AceCS1); and the conversion from citrate to acetyl-CoA by ATP citrate lyase (ACL). ${ }^{98}$ Acetyl-CoA is utilized extensively as a cofactor for enzymes that catalyze the transfer of an acetyl group, including HATs that utilize the acetyl group of acetyl-CoA to form $\varepsilon-N$-acetyl-lysine. Intracellular concentrations of acetyl-CoA can vary roughly $\sim 10$-fold under normal physiological conditions and it falls within the $K_{\mathrm{m}}$ range of HATs. Histone acetylation activity is thus dynamically regulated by availability of acetyl CoA.

Both absolute acetyl-CoA and the ratio of acetyl-CoA to coenzyme $A$ have been shown to regulate histone acetylation in cancer. ${ }^{99,100}$ Availability of acetyl-CoA for HATs is primarily modulated by 1) ACL expression; and 2) the availability of citrate as a substrate for ACL. ACL protein expression is localized to the nucleus and its activity contributes to nuclear specific acetyl-CoA pool. $^{100} \mathrm{ACL}$ silencing in HCT116 cells suppressed histone acetylation for all core histones, whereas the knockdown of AceCS1 had no effect. Non-histone protein acetylation was unaltered, suggesting that ACL-derived acetyl-CoA has a specific role in regulating histone acetylation. Cancer cells often overexpress $A C L^{101}$ and this probably contributes to nuclear acetylCoA pool that is necessary for histone acetylation and expression of glycolytic enzymes. Oncogene-driven metabolic reprogramming in cancers also promotes a high level of glycolytic flux and mitochondrial production of citrate, which translocates to the cytosol and nucleus. In mouse pancreas, expression of constitutive activated $\mathrm{KRAS}^{\mathrm{G} 12 \mathrm{D}}$ allele resulted in high histone $\mathrm{H} 3$ and $\mathrm{H} 4$ acetylation in pancreatic adenocarcinoma. ${ }^{99} \mathrm{KRAS}^{\mathrm{G} 12 \mathrm{D}}$ dependent activation of AKT promoted nuclear acetyl-CoA accumulation via (1) induction of glycolysis, leading to overproduction of citrate; and 
(2) ACL phosphorylation and activation. Indeed, constitutively active AKT induced a rapid and pronounced rise histone acetylation in cancer cells, ${ }^{99}$ further confirming its role in mediating histone acetylation.

Another player involved in histone acetylation is MYC. MYC has been shown to upregulate the expression of HAT-GCN5, which induced mono-, di-, tri-, and tetra-acetylation of histone $\mathrm{H} 4 \mathrm{~N}$ terminal. ${ }^{102}$ Besides, MYC mediates gene expression of metabolic enzymes linked to acetyl-CoA synthesis, including glycolysis and glutaminolysis. In isogenic rat fibroblasts with $\mathrm{Myc}^{-/-}$or $\mathrm{Myc}^{+/+}$, it was demonstrated that Myc increased the mitochondrial export of acetyl-groups and a majority of these acetyl equivalents ended up in histone H4-K16. ${ }^{103}$ These data emphasizes the role of Myc in modulating the gene expression of HATs and the availability of acetyl-CoA to support histone acetylation in response to proliferative signals. Hence, multiple oncogenic signals contribute to increased histone acetylation to regulate gene expression.

$N A D^{+} . \mathrm{NAD}^{+}$is essential for the deacetylation activity of sirtuins, a subgroup of $\mathrm{HDAC}$, and changes in $\mathrm{NAD}^{+} / \mathrm{NADH}$ ratio is thought to positively regulate activity of sirtuins. $\mathrm{NAD}^{+} / \mathrm{NADH}$ ratio is closely associated with energy status in cells. When energy is plentiful, $\mathrm{NAD}^{+} / \mathrm{NADH}$ ratio drops; while $\mathrm{NAD}^{+}$level can be induced in nutrient deprived conditions. Hence, through sensing of $\mathrm{NAD}^{+} / \mathrm{NADH}$ levels, sirtuins serves as a link between energy status and regulation of gene expression. ${ }^{104}$ High glycolytic activity in cancers often generates a low $\mathrm{NAD}^{+} / \mathrm{NADH}$ ratio that is inhibitory for sirtuins. Repressed sirtuins, together with increased HATs activity induced by acetyl-CoA, may contribute to histone hyperacetylation and aberrant gene transcription. More studies are needed to understand the role of metabolic status and sirtuin activation in cancer.

Hexosamine biosynthetic pathway promotes protein glycosylation O-GlcNAcylation is one of the most common post-translational modifications in eukaryotic cells, via attachment of $O$-linked $\beta$-D-N-acetylglucosamine (O-GlcNAc) to Ser/Thr residue. O-GlcNAcylation is regulated by competing actions of O-GlcNAc transferase (OGT) and O-GlcNAcase (OGA), which, respectively, catalyzes addition and removal of $O$-GlcNAc from proteins. Recent evidence indicate that modifications of all core histone proteins by $O$-GICNAc constitute part of the histone code. ${ }^{105-108}$ OGT has been shown to coordinate with TETs to modulate O-GlcNAcylation of histone $\mathrm{H} 2 \mathrm{~B}$ to activate gene transcription; ${ }^{109,110}$ whereas its association with $\mathrm{EZH} 2$ in polycomb repressive complex 2 regulates H3K27 me3 to silence tumor suppressor genes. ${ }^{111}$ Alternatively, OGT activates gene transcription via O-GlcNAcylation of C-terminal domain of RNA polymerase II. ${ }^{112}$ Elevated OGT expression and protein hyper-O-GlcNAcylation is a common feature in human cancers. ${ }^{113}$ Cell metabolism has a crucial role in O-GlcNAcylation via modulating the biosynthesis of uridine diphosphate $\beta-D-N$-acetylglucosamine (UDP-GlcNAc), the activated substrate for O-GlcNAcylation.

O-GlcNAc. O-GlcNAc is synthesized via the hexosamine biosynthetic pathway (HBP). In this pathway, glucose entering glycolysis is first metabolized to glucose-6-phosphate (glucose-6-P) and then fructose-6-phosphate (fructose-6-P). About $2-5 \%$ of the fructose6-P will be diverted to fructose-6-P amidotransferase (GFAT), the first and rate limiting enzyme of HBP. GFAT converts fructose-6-P to glucosamine-6-phosphate $\left(\mathrm{GlCNH}_{2}-6-\mathrm{P}\right)$ utilizing an amine group from glutamine. A sequence of reactions then adds an acetyl group from acetyl-CoA and UDP from UTP results in production of UDP-GlcNAc. Hence, HBP integrates substrates from carbohydrate, amino acid, fat and nucleotide metabolism. Glycolysis and supply of glutamine have a pivotal role in UDPGlcNAc synthesis, as they are obligatory for the rate limiting reaction catalyzed by GFAT. Cancer cells frequently demonstrate the upregulation of HBP, which is in turn associated with aberrant O-GlcNAcylation and increased malignant behavior. ${ }^{114-118}$ The upregulation of HBP in cancer cells is primarily driven by an increased glucose uptake and metabolism. In $\mathrm{KRAS}^{\mathrm{G} 12 \mathrm{D}}$-driven pancreatic cancer, KRAS ${ }^{\mathrm{G} 12 \mathrm{D}}$ promotes glucose utilization via increased expression of glucose transporter 1 (Glut1), hexokinase 1 $(H k 1)$ and hexokinase $1(H k 2)$, which induce metabolic flux through GFAT and protein O-GICNAcylation. ${ }^{30}$ KRAS $^{\text {G12D }}$ inactivation, in contrast, downregulated global protein glycosylation, suggesting that KRAS ${ }^{\mathrm{G} 12 \mathrm{D}}$-mediated glucose utilization via HBP is essential for O-GlcNAcylation. In another study, tumor hypoxia was found to co-ordinately upregulation of glucose and glutamine utilization via HBP, which increased protein O-GlcNAcylation required for tumor survival. ${ }^{119}$ Conversely, glucose deprivation suppressed $\mathrm{O}$-GlcNAcylation and cell growth, an effect reversed by addition of $\mathrm{N}$-acetylglucosamine, a HBP substrate. These studies confirm the role of accelerated glucose metabolic in protein $O-G l c N A c y l a t i o n$ in cancer cells.

\section{EPIGENETIC REGULATION OF METABOLIC GENES EXPRESSION IN CANCERS}

DNA methylation

DNA methylation has been shown to modulate the expression of metabolic genes directly by regulating their transcription or indirectly via dysregulation of oncogenic cascades (for example, AKT, AMPK and HIF). DNA methylation mediates silence of fructose-1,6-bisphosphatase 1 (FBP1) and fructose-1,6-bisphosphatase 2 (FBP2) via promoter methylation in breast, gastric, liver and colorectal cancers. ${ }^{120-123}$ FBP1 and FBP2 are rate limiting enzymes for gluconeogenesis that antagonize glycolysis, and their decreased expression promotes glycolytic flux for driving macromolecules biosynthesis and ATP production. DNA methylation also mediates overexpression of glucose transporter 1 (GLUT1) by epigenetic loss of Derlin-3, a key gene involved in the proteasomal degradation of GLUT1. ${ }^{124}$ Conversely, promoter hypomethylation contributes to upregulation of pyruvate kinase ioszyme 2 (PKM2) in multiple cancer types. ${ }^{125}$ PKM2 is a less active isomer that drives glucose flux towards macromolecules biosynthesis and is the predominant isoform in actively proliferating cells. DNA methylation also drives transcriptional silencing of tumor suppressor genes involved in signaling cascades linked to tumor metabolism. $\mathrm{PI} 3 \mathrm{~K} / \mathrm{AKT} / \mathrm{mTOR}$ and HIF-1 signaling are central activators of glycolysis and cancer-related metabolism. Multiple tumor suppressors that repress $\mathrm{PI} 3 \mathrm{~K} / \mathrm{AKT} / \mathrm{mTOR}$ and HIF-1 signaling are epigenetically silenced by promoter hypermethylation, including PTEN $^{126-130}$ LKB1, $^{131,132} \mathrm{VHL}^{133-136}$ and prolyl hydroxylases (PHD1/2/3). ${ }^{137,138}$ Hence, differential DNA methylation significantly contributes to glycolytic phenotype in human cancers.

\section{Histone modifications}

Among the histone modification enzymes, the role of sirtuins (SIRTs) in regulating cell metabolism has been most extensively investigated. SIRT6 regulates glucose homeostasis by modulating histone acetylation. ${ }^{139}$ SIRT6 interacts directly with HIF1 and MYC, and it functions as a co-repressor through histone deacetylation, thereby inhibiting transcription. ${ }^{139-142}$ SIRT6 hence acts as a tumor suppressor by repressing HIF-dependent glycolytic switch and MYC-dependent ribosome biogenesis and glutaminolysis. SIRT6 knockout induced a shift towards a 'glycolytic phenotype' and promoted cancer formation and aggressiveness. Consistent with its tumor suppressive role, frequent deletions in SIRT6 have been detected in cancer cell lines and colon, pancreatic and hepatocellular cancers. ${ }^{143}$ SIRT7 is another sirtuin that directly interacts with MYC. ${ }^{144,145}$ SIRT7 possesses selective catalytic activity towards H3K18Ac. As H3K18 deacetylation is a repressive mark, it is not surprising that SIRT7 opposes MYC- dependent gene 
regulation and thus suppresses MYC-mediated metabolic alternations. In contrast to SIRT6/7, SIRT2 promotes deregulated metabolism through indirectly stabilizing MYC. ${ }^{146}$ SIRT2 deacetylases histone at H4K16, leading to suppressed expression of ubiquitin-protein ligase NEDD4. NEDD4 is a negative regulator of MYC by targeting it for ubiquitination and degradation. Critically, SIRT2 is itself upregulated by MYC in cancer cell lines; it constitutes a positive-feedback loop that promotes MYC-dependent transcription and oncogenesis. Given the myriad of histone modifications that contributes to gene regulation, much remains to be understood with regards to the role of histone code on metabolic reprogramming in cancer.

miRNA

MicroRNAs (miRNAs) regulate expression of genes involved in diverse cellular functions. Several aspects of cell metabolism are regulated by miRNAs, including glycolysis and mitochondrial TCA cycle, thereby contributing to the Warburg's effect. miRNAs also have a major impact on the signal transduction via PI3K/AKT, HIF1 and Myc that contribute to the metabolic phenotype in human cancers. miRNAs regulates the expression of numerous genes taking part in glucose uptake, including miR-1291 for GLUT1, ${ }^{147}$ miR-195-5p and miR-106a for GLUT3, ${ }^{148,149}$ and miR-93 for GLUT4. ${ }^{150}$ as well as glycolysis, such as miR-143, miR-145 and miR-155 for hexokinase 2 (HK2), ${ }^{151-156}$ miR-200 for glucose-6-P isomerase $(\mathrm{GPI}){ }^{157} \mathrm{miR}-15 \mathrm{a} / 16-1$ and $\mathrm{miR}-122$ for aldolase $A$ (ALDOA), ${ }^{158}$ miR-326 and miR133a/b for PKM2. ${ }^{159,160}$ Glutaminolysis is also targeted by miRNAs (miR-23a/b) via glutaminase. ${ }^{161}$ Deregulation of aforementioned miRNAs has been reported in cancers and they contribute to increased glycolysis and glutaminolysis in cancers. Moreover, miR-210, by repressing iron-sulfur cluster assembly proteins (ISCU1/2), inhibits mitochondrial function. miR-210 therefore favors a shift towards a glycolytic phenotype and lactate production, which is critical for adaptation to hypoxic tumor microenvironment. ${ }^{162}$ miRNAs also have a profound effect on signal transduction. PI3K/AKT/mTOR, LKB1/ AMPK, MYC, and HIF1 signaling cascades have all been shown to be regulated by miRNAs. Hence, the dysregulation of metabolic signaling pathways by miRNAs additionally contributes to altered metabolism in cancers.

\section{THERAPEUTIC OPPORTUNITIES TARGETING EPIGENETIC- METABOLISM CROSSTALKS IN CANCER}

Reversal of epigenetic dysregulation by targeting cancer metabolism

Glycolysis inhibitors. Accelerated glycolysis in cancer contributes to histone acetylation via citrate and acetyl CoA. Histone acetylation in cells is regulated by glucose flux in a dosedependent manner ${ }^{163}$ and elevated glycolysis in cancer is associated with global histone hyperacetylation. ${ }^{164}$ Inhibition of glycolysis holds promise for modulating histone acetylation. 2-Deoxyglucose (2-DG) is a glucose analog that is transported to cells and metabolized by hexokinase (HK) to form 2-DG-P. 2-DG-P cannot be further metabolized by phosphohexose isomerase, ${ }^{165}$ leading to the feedback inhibition of hexokinase, a rate-limiting enzyme for glycolysis. Treatment with 2-DG significantly suppresses acetyl-CoA levels, and the acetylation of histone $\mathrm{H} 3, \mathrm{H} 4$, $\mathrm{H} 2 \mathrm{~A}$ and $\mathrm{H} 2 \mathrm{~B}$ in multiple cancer cell lines. ${ }^{164}$ The reductions in global histone acetylation by 2-DG compromise DNA repair and sensitize cancer cells to DNA-damaging therapeutics. Acetyl-CoA is also required for maintenance of pluripotency through histone acetylation and glycolysis inhibition by 2-DG or 3-bromopyruvate (BrPA, a GAPDH inhibitor), which was found to induce differentiation in embryonic stem cells. ${ }^{166}$ Hence, glycolysis represents a viable target for modulating histone acetylation.
Glutaminolysis inhibitors. Glutaminolysis is frequently elevated in cancer, and accumulating evidence indicates that its inhibition is effective for targeting glutamine-addicted cancers. ${ }^{5}$ Glutaminase (GLS), which catalyzes the deamination of glutamine to glutamate, is the most extensively studied drug target in this pathway. Several inhibitors, such as bis-2-(5-phenylacetamido1,2,4-thiadiazol-2-yl) ethyl sulfide (BPTES), ${ }^{167}$ compound $968^{168}$ and CB- $839^{167}$ have been characterized, and CB-839 is currently undergoing Phase I dose escalation trials in solid and hematological malignancies (Table 1). Glutaminolysis generates a-KG, TCA cycle intermediates and acetyl-CoA, which in turn influence epigenetic status. Indeed, treatment of breast cancer cells with compound 968 significantly altered histone H4K16 acetylation and histone $\mathrm{H} 3 \mathrm{~K} 4$ methylation, leading to downregulation of numerous cancer-related genes. ${ }^{169,170}$ Using an unbiased small molecule screen, Elhammali et al. ${ }^{171}$ unravelled Zaprinast, a phosphodiesterase 5 inhibitor, as a potent inhibitor of mutant $\mathrm{IDH} 1^{\mathrm{R} 132 \mathrm{C}}$-mediated 2-HG biosynthesis in HT1080 cells. Surprisingly, Zaprinast did not target mutant IDH1, but instead it suppressed GLS. GLS-mediated glutaminolysis is essential for maintaining supply of $\mathrm{a}-\mathrm{KG}$, upstream of IDH1/2 metabolism of $\mathrm{a}-\mathrm{KG}$ to $2-\mathrm{HG}$. As a consequence, Zaprinast treatment resulted in a marked reduction in histone $\mathrm{H} 3 \mathrm{~K} 9 \mathrm{me} 2 / 3$ methylation. These studies highlight potential utility of GLS inhibitors in the reversal of epigenetic dysregulation in cancer, especially in the context of IDH1/2 mutations.

IDH1/2 inhibitors. Inhibition of IDH1/2 has been pursued as a strategy to suppress the production of oncometabolite 2-HG. Rohle et al. ${ }^{172}$ described the first selective inhibitor (AGI-5198) of mutant IDH1, ${ }^{\text {R132H }}$ which selectively inhibited mutant IDH1 $\left(\mathrm{IC}_{50}=70 \mathrm{~nm}\right)$, but not wild-type IDH1 or any of the IDH2 isoforms $\left(\mathrm{IC}_{50}>100 \mu \mathrm{m}\right)$. In IDH1-mutant glioma cells, AGI-5198 inhibited $2-\mathrm{HG}$ production and cell growth in vitro and in vivo. AGI-5198 induced demethylation of $\mathrm{H} 3 \mathrm{~K} 9 \mathrm{me} 3$ and $\mathrm{H} 3 \mathrm{~K} 27 \mathrm{me} 3$, whilst it had no effect on DNA methylation. AGI-5198 also demonstrated anticancer activity in human chondrosarcoma cells harboring IDH1 mutations. ${ }^{13}$ Subsequently, novel mutant IDH1 $1^{\mathrm{R} 132 \mathrm{H}}$ inhibitors has been reported, such as AG-120, AG-881, ML309, ${ }^{174}$ 2-(3-trifluoromethylphenyl)isothioazol-3(2H)-one, ${ }^{175}$ bis imidazole phenol (cpd 1), ${ }^{176}$ 1-hydroxypyridin-2-one compounds ${ }^{177}$ and GSK321 and GSK $864^{178}$ (Table 1). These drugs inhibited mutant IDH1 ${ }^{132 \mathrm{H}}$ in nanomolar range and exhibited promising selectivity over wild type IDH1.

AG-221 is a first-in-class inhibitor of mutant IDH2 $2^{179}$ (Table 1). AG-221 was found to suppress 2-hydroxyglutarate (2-HG) levels in hematopoietic cells expressing mutant $\mathrm{IDH} 2^{\mathrm{R} 140 \mathrm{Q}}$, and in murine models of IDH2-mutant leukemia. Consistent with its role in epigenetic dysregulation, mutant IDH2 inhibition with AG-221 reversed DNA hypermethylation in LSK stem cells from mice expressing mutant IDH2. Notably, AG-211 induced cell differentiation in leukemia cells from IDH2-mutant expressing mice and it synergized with Flt3 inhibition to reduce leukemic cell burden in vivo. AG-211 also demonstrated a survival benefit in primary human IDH2 mutant AML xenografts. ${ }^{180,181}$ AG-211 has since been introduced into Phase I clinical trials and a Phase III trial has been initiated in 2015. Interim results presented thus far suggest that AG-211 is highly effective in decreasing plasma and bone marrow 2-HG levels and achieved durable remission in some patients with IDH2 mutant advanced hematologic malignancies. ${ }^{182}$ AGI-6780 is another selective inhibitor towards mutant IDH2 ${ }^{\mathrm{R} 140 \mathrm{Q}} \cdot{ }^{183} \mathrm{AGI}-6780$ treatment in $\mathrm{IDH} 2$ mutant cells resulted in histone and DNA demethylation, ${ }^{184}$ and reversed gene signatures caused by epigenetic dysregulation. These proof-of-concept studies indicate that targeting of mutant IDH1/IDH2 has potential clinical applications as a differentiation therapy in cancers bearing mutant forms of these proteins. 


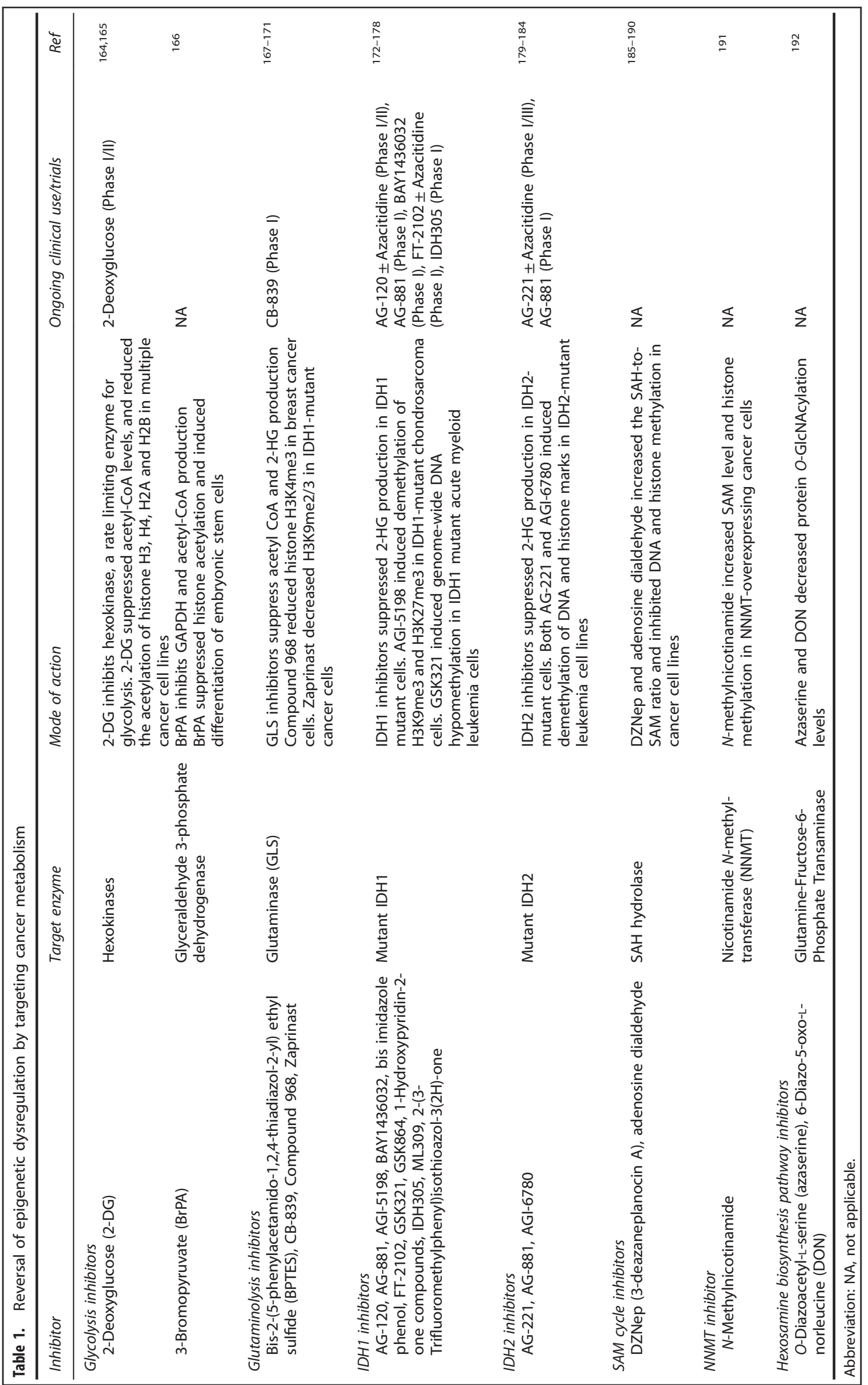


SAM cycle inhibitors: As the availability of SAM is critical for the activities of DNMTs and HMTs, SAM cycle blockade will likely affect DNA and histone methylation. S-adenosylhomocysteine hydrolase (SAH hydrolase) participates in the activated methyl cycle through catalyzing the hydrolysis of SAH into adenosine and homocysteine. SAH hydrolase is essential for the maintenance of methylation homeostasis, as SAH caused the byproduct inhibition of DNMTs and HMTs. DZNep (3-deazaneplanocin A) was first identified as a SAH hydrolase inhibitor, ${ }^{185}$ and subsequent studies showed that DZNep treatment in cancer cell lines globally inhibited DNA and histone methylation, an effect that is nonselective. ${ }^{186}$ Another SAH hydrolase inhibitor (adenosine dialdehyde) also had the similar impact on DNA and histone methylation. EZH2, an oncogenic HMT that methylates histone H3K27 and facilitates transcriptional repression, is indirectly targeted by DZNep in cancer cells via SAH hydrolase inhibition. DZNep treatment reactivates a subset of developmental genes, but it is ineffective towards genes silenced by dense promoter methylation. Hence, combination of DZNep with 5-aza-2'-deoxycytidine (5-Aza), a DNMT inhibitor, has shown synergistic anticancer activity in leukemia and colorectal cancer, ${ }^{187-190}$ by activating genes that are aberrantly silenced by histone and DNA methylation.

NNMT inhibitor: As NNMT overexpression induced SAM depletion and histone hypomethylation, it might be a potential drug target in NNMT-overexpressing cancer cells. $\mathrm{N}$-methyl-nicotinamide, a reaction side product of NNMT, is a specific and potent inhibitor towards NNMT. Indeed, NNMT inhibition in vivo using $\mathrm{N}$-methylnicotinamide is able to increase histone methylation at H3K4 and increased methylated H3K4 occupancy at gene promoters. ${ }^{191}$ Thus, inhibition of NNMT is a viable approach for modification of histone methylation.

Hexosamine biosynthesis pathway inhibitors: UDP-GICNAc, the substrate for protein O-GlcNAcylation, is synthesized via HBP. GFAT is the rate-limiting enzyme in HBP that can be targeted by well characterized inhibitors, O-diazoacetyl-L-serine (azaserine) and 6-diazo-5-oxo-L-norleucine (DON). ${ }^{192}$ Cancer cells cultured under high glucose exhibited increased HBP pathway flux and protein $O$-GlcNAcylation, which mediates transcriptional activation of $\beta$-catenin, thereby promoting the $\mathrm{Wnt} / \beta$-catenin signaling and cell proliferation. ${ }^{193-195}$ Treatment with either azaserine or DON decreased protein O-GlcNAcylation level, reduced $\beta$-catenin expression and reversed glucose-mediated cell proliferation. ${ }^{193,194}$ Protein O-GlcNAcylation has also been shown to be upregulated in $\mathrm{CD}_{133^{+}}$cancer stem cells. ${ }^{196}$ Inhibition of $\mathrm{HBP}$ using azaserine reduced the $\mathrm{CD}_{133^{+}}$subpopulation and CD133 expression; whereas treatment with $\mathrm{N}$ - $\mathrm{N}$-acetylglucosamine (GlcNAc, which promotes HBP) had a reverse effect. It will be of great interest to investigate whether intervention of HBP will impact epigenetic regulators and histone modifications.

\section{Modulation of cancer metabolism using epigenetic drugs}

DNMT inhibitors. DNA methylation can be therapeutically targeted using DNMT inhibitors. Two inhibitors of DNMT, 5-azacytidine and 5-aza-2'-deoxycytidine, have been clinically approved by FDA for treatment of myelodysplastic syndrome, and the latter has been approved for acute myeloid leukemia (AML). Clinical trials (Phase I-III) have also been conducted in several solid malignancies (Table 2). These are cytosine analogues that nonselectively inactivate DNMT1, DNMT3A and DNMT3B. ${ }^{197}$ it is largely unknown whether DNMT inhibitors can have a metabolic effect on cancer. Given the non-specific nature of these DNA methylation inhibitors and their widespread effect on gene expression, it will be important to elucidate their roles in cancer metabolism. DNMT inhibitors may be useful in reversing DNA methylation induced by metabolic alteration. IDH1/2-mutant cancers, which exhibit DNA hypermethylation, are sensitive to 5-azacytidine and 5-aza-2'-deoxycytidine. 5-Azacytidine induced tumor regression in a patient-derived IDH1 mutant glioma xenograft model; ${ }^{198}$ while 5 -aza-2'-deoxycytidine effectively suppressed growth in IDH-mutant glioma cells in vitro and in vivo. ${ }^{199}$ DNMT inhibitors reversed the hypermethylator phenotype and resulted in cell differentiation and slowed growth. In the latter study, 5-aza-2'-deoxycytidine was actually shown to be more effective than IDH inhibitors in inducing the differentiation of IDHmutant glioma cells. Hence, targeting the methylome may be a complementary approach to counteract the effect of oncometabolites in cancers.

HDAC inhibitors. HDAC inhibitors represent a diverse class of compounds that inhibit HDACs activity. Two HDAC inhibitors Vorinostat and Romidepsin have been approved for cutaneous T-cell lymphoma, and their use in solid tumors is an area of active investigation (Table 2). HDAC inhibitors induce histone acetylation and reverse gene silencing by HDACs in human cancers. Emerging evidence suggests that inhibition of HDACs may impact cancer metabolism. In HT29 colorectal cancer cells, treatment with HDAC inhibitors butyrate or trichostatin A was associated with a significant reduction in glucose uptake, glycolysis flux and lactate production. ${ }^{200}$ In multiple myeloma cells, Vorinostat or valproic acid treatment suppressed GLUT1 expression and inhibited hexokinase I activity. ${ }^{201}$ In H460 lung cancer cells, butyrate or trichostatin A treatment suppressed glycolysis and triggered a shift in metabolism away from glycolysis by activating mitochondrial metabolism. ${ }^{202}$ Butyrate also attenuated glycolysis in breast cancer cells. ${ }^{203}$ These results suggest that inhibition of HDAC may promote the reversion of glycolytic phenotype in cancer cells.

Sirtuin activators and inhibitors. Despite their importance in metabolic regulation in cancers, limited attention has been paid to the potential use of sirtuin activators and inhibitors to influence cancer metabolism. Sirtuin 6 (SIRT6), a tumor suppressor that opposes glycolysis, has been shown to be activated by free fatty acids (myristic, oleic and linoleic acids) up to $\leqslant 35$-fold. ${ }^{204}$ Discovery of small molecule activators of SIRT6 may unveil a novel approach to target tumor metabolism. On the other hand, several inhibitors that block oncogenic Sirtuin 2 (SIRT2) has been described. ${ }^{205}$ Further investigations are required to define the effect of sirtuin activators and inhibitors on cancer metabolism and their role in cancer management.

miRNA. Modulation of miRNAs holds promise as therapeutic targets, given its regulatory roles in the dysregulation of metabolism in carcinogenesis. Currently, there are two approaches to target miRNAs. Aberrantly silenced miRNAs can be restored using synthetic miRNA mimics; although overexpressed miRNAs can be silenced using miRNA sponges or antisense oligonucleotides. ${ }^{206-208}$ Both approaches have been utilized to manipulate metabolic genes in cancer. As an example, the reexpression of miR-143, which targets hexokinase II 3'-untranslated region, overturned the glycolytic phenotype and inhibited cancer growth. ${ }^{154}$ On the contrary, oncogenic miRNAs that target LKB1/ AMPK or PTEN tumor suppressive pathways may represent attractive targets for the design of therapeutic anti-miRNAs. For instance, anti-miR-21-mediated inhibition (which targets PTEN tumor suppressor), restored PTEN expression in hepatocellular cancer and contributed to treatment. ${ }^{209}$ One major challenge facing miRNA-targeting focuses on the safe and efficient delivery of miRNA mimics and anti-miRNAs. ${ }^{210}$ Advances in delivery technology will accelerate realization of miRNA-based therapeutics in the clinical practice. 


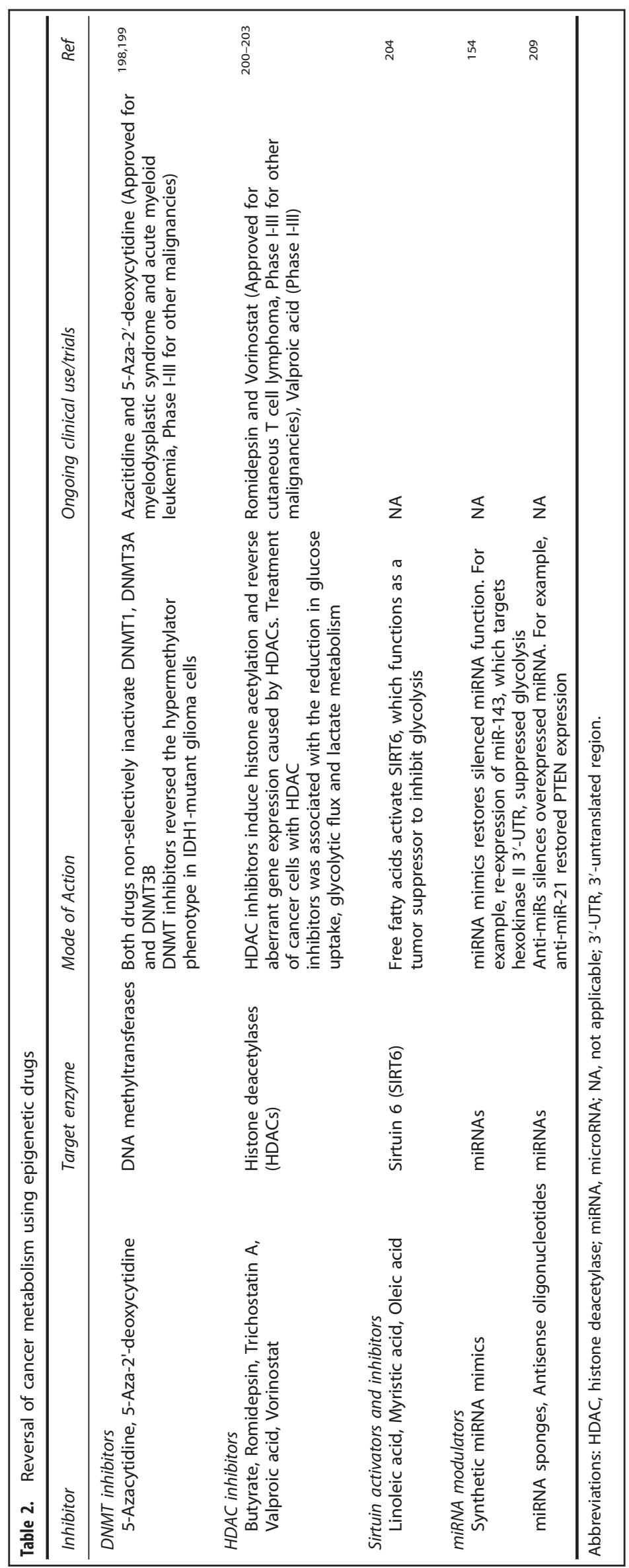


Impact of tumor microenvironment and metabolism on epigenetic therapy

Epigenetic drugs, including DNMT and HDAC inhibitors, have been approved by the FDA for use in hematological malignancies. However, the use of these drugs has been met with limited success in solid tumors thus far. Several Phase I clinical trials that examined the pharmacodynamics of DNA demethylation drugs or histone deacetylase inhibitors indicated the reversal of epigenetic abnormalities in solid tumors following drug treatment. ${ }^{211-213}$ However, the therapeutic effects of epigenetic therapies towards solid tumors has been disappointing. Solid tumors, unlike hematological malignancies, are characterized by regions of hypoxia (low oxygen), which has a key role in tumor progression, aggressiveness and drug resistance.214,215 Hypoxic tumor cells display epigenetic abnormalities. ${ }^{216-220}$ Hypoxia is associated with DNA hypomethylation. Hypoxia has been shown to downregulate the expression of DNMT1, DNMT3A and DNMT3B in human colorectal cancer cells. ${ }^{217}$ On the contrary, hypoxia results in HIF-dependent transcriptional activation of TET1. ${ }^{219,220}$ Given that a hypoxic tumor microenvironment promotes DNA hypomethylation, efficacy of DNA demethylation agents, such as modulators of DNMTs/TETs, are likely suppressed in solid tumors as compared to hematological malignancies. On the other hand, hypoxia induces histone hypoacetylation that may be potentially targeted by inhibitors of HDAC. ${ }^{221}$ Indeed, HDAC inhibitors such as Vorinostat and valproic acid have shown promising results in solid tumors, especially given in combination with chemotherapeutic agents. $22-225$ Therefore, approaches to target epigenetic mechanisms should take into consideration of the potential impact of the tumor microenvironment and metabolism.

\section{CONCLUSION AND 5-YEAR VIEW}

Crosstalks between epigenetics and metabolism are fundamental aspects of cellular adaptation to nutrition status. The human epigenome is dynamically regulated by the metabolome. Alterations in either the epigenome or metabolome arising from genetic mutation may therefore coordinately drive aberrant gene expression, which in turn, contributes to tumor development and progression. Here we have outlined potential strategies that target crosstalks between epigenome and metabolome that might be exploited to selectively inhibit tumorigenesis. At present, much of our knowledge has been gathered in simplistic in vitro cell culture systems that might poorly reflect the complex interaction of epigenome and metabolome in vivo. In the future, preclinical studies need to better define their crosstalk in context of the tumor microenvironment that consists of stromal and immune components and to validate potential targets using appropriate in vivo models, which ultimately will contribute to development of novel therapeutic targets for intervention.

With numerous drugs targeting metabolism in the drug development pipeline, in the next 5 years we will be able to effectively target these abnormalities in cancer. Novel drugs targeting mutant IDH1/2, for example, are already undergoing phase II/III trials with treatment of advanced leukemia harboring these mutations. With the promising preliminary data, IDH1/2 inhibition represents a highly specific therapy for this subset of cancers. ${ }^{183,184}$ Metabolic reprogramming in cancer cells might also be targeted by epigenetic drugs such as DNMT and HDAC inhibitors. However, targeting epigenetic machinery likely has a broad impact on gene expression, and more studies are needed to define their specific effects on tumor metabolism. A caveat of targeted therapies, as exemplified by the development of tyrosine kinase inhibitors, is that they are useful only when their target(s) are the main drivers of carcinogenesis. To fully realize the potential of metabolic/epigenetic modulators, future clinical trials should incorporate analysis of biomarkers to unravel epigenomic
(DNA methylation and histone lysine acetylation) and metabolomic (metabolites) markers that allow the selection of subsets of patients that may benefit most from these treatments. Given the extensive crosstalk between epigenetics and metabolism, perhaps it is the development of combinatorial approaches involving metabolism inhibitors and epigenetic modulators might achieve synergistic tumor inhibition. Notably, mutant IDH1/2 inhibitors are being evaluated in Phase I/II clinical trials with inhibitors of DNMTs (Table 1), with the rationale being that they might promote active DNA demethylation and suppress DNA methylation, respectively, to reverse DNA methylation in IDH1/2-mutant cancers. Development of rationale drug combinations involving metabolism inhibitors, epigenetic modulators and traditional chemotherapeutics will likely have the greatest impact on future cancer management.

\section{CONFLICT OF INTEREST}

The authors declare no conflict of interest.

\section{ACKNOWLEDGEMENTS}

This project was supported by research funds from RGC-GRF (14114615 and 766613) from Hong Kong; Shenzhen Municipal Science and Technology R\&D fund (JCYJ20130401151108652) and Shenzhen Virtual University Park Support Scheme to the Chinese University of Hong Kong, Shenzhen Research Institute; National Natural Science Foundation of China (81502064).

\section{REFERENCES}

1 Warburg O. On the origin of cancer cells. Science 1956; 123: 309-314.

2 Kim JW, Dang CV. Cancer's molecular sweet tooth and the Warburg effect. Cancer Res 2006; 66: 8927-8930.

3 Vander Heiden MG, Cantley LC, Thompson CB. Understanding the Warburg effect: the metabolic requirements of cell proliferation. Science 2009; 324: 1029-1033.

4 Dang CV. Glutaminolysis: supplying carbon or nitrogen or both for cancer cells? Cell Cycle 2010; 9: 3884-3886.

5 Jin L, Alesi GN, Kang S. Glutaminolysis as a target for cancer therapy. Oncogene 2015; 35: 3619-3625.

6 Wise DR, DeBerardinis RJ, Mancuso A, Sayed N, Zhang XY, Pfeiffer HK et al. Myc regulates a transcriptional program that stimulates mitochondrial glutaminolysis and leads to glutamine addiction. Proc Natl Acad Sci USA 2008; 105: 18782-18787.

7 Hensley CT, Wasti AT, DeBerardinis RJ. Glutamine and cancer: cell biology, physiology, and clinical opportunities. J Clin Invest 2013; 123: 3678-3684.

8 Wong CC, Qian Y, Li X, Xu J, Kang W, Tong JH et al. SLC25A22 promotes tumorigenicity and metastasis of KRAS-mutant colorectal cancer by regulating intracellular aspartate biosynthesis. Gastroenterology 2016; 151: 945-960.

9 Barthel A, Okino ST, Liao J, Nakatani K, Li J, Whitlock JP Jr et al. Regulation of GLUT1 gene transcription by the serine/threonine kinase Akt1. J Biol Chem 1999; 274: 20281-20286.

10 Yun J, Rago C, Cheong I, Pagliarini R, Angenendt P, Rajagopalan H et al. Glucose deprivation contributes to the development of KRAS pathway mutations in tumor cells. Science 2009; 325: 1555-1559.

11 Morani F, Phadngam S, Follo C, Titone R, Aimaretti G, Galetto A et al. PTEN regulates plasma membrane expression of glucose transporter 1 and glucose uptake in thyroid cancer cells. J Mol Endocrinol 2014; 53: 247-258.

12 Miyamoto S, Murphy AN, Brown JH. Akt mediates mitochondrial protection in cardiomyocytes through phosphorylation of mitochondrial hexokinase-Il. Cell Death Differ 2008; 15: 521-529.

13 Deprez J, Vertommen D, Alessi DR, Hue L, Rider MH. Phosphorylation and activation of heart 6-phosphofructo-2-kinase by protein kinase $B$ and other protein kinases of the insulin signaling cascades. J Biol Chem 1997; 272: 17269-17275.

14 Osthus RC, Shim H, Kim S, Li Q, Reddy R, Mukherjee M et al. Deregulation of glucose transporter 1 and glycolytic gene expression by c-Myc. J Biol Chem 2000; 275: 21797-21800.

15 David CJ, Chen M, Assanah M, Canoll P, Manley JL. HnRNP proteins controlled by c-Myc deregulate pyruvate kinase mRNA splicing in cancer. Nature 2010; 463: 364-368. 
16 Yan H, Parsons W, Jin G, McLendon R, Rasheed A, Yuan W et al. IDH1 and IDH2 mutations in gliomas. $N$ Engl J Med 2009; 360: 765-773.

17 Figueroa ME, Abdel-Wahab O, Lu C, Ward PS, Patel J, Shih A et al. Leukemic IDH1 and IDH2 mutations result in a hypermethylation phenotype, disrupt TET2 function, and impair hematopoietic differentiation. Cancer Cell 2010; 18: 553-567.

18 Astuti D, Latif F, Dallol A, Dahia PL, Douglas F, George E et al. Gene mutations in the succinate dehydrogenase subunit SDHB cause susceptibility to familial pheochromocytoma and to familial paraganglioma. Am J Hum Genet 2001; 69: 49-54.

19 Toro JR, Nickerson ML, Wei MH, Warren MB, Glenn GM, Turner ML et al. Mutations in the fumarate hydratase gene cause hereditary leiomyomatosis and renal cell cancer in families in North America. Am J Hum Genet 2003; 73: 95-106.

20 Hanahan D, Weinberg RA. Hallmarks of cancer: the next generation. Cell 2011; 144: 646-674.

21 Jaenisch R, Bird A. Epigenetic regulation of gene expression: how the genome integrates intrinsic and environmental signals. Nat Genet 2003; 33S: 245-254.

22 Feil R, Fraga MF. Epigenetics and the environment: emerging patterns and implications. Nat Rev Genet 2011; 13: 97-109.

23 Herceg Z, Vaissiere T. Epigenetic mechanisms and cancer: an interface between the environment and the genome. Epigenetics 2011; 6: 804-819.

24 Gupta V, Gopinath P, Iqbal MA, Mazurek S, Wellen KE, Bamezai RN. Interplay between epigenetics \& cancer metabolism. Curr Pharm Des 2014; 20: 1706-1714.

25 Johnson C, Warmoes MO, Shen X, Locasale JW. Epigenetics and cancer metabolism. Cancer Lett 2015; 356: 309-314.

26 Munoz-Pinedo C, Gonzalez-Suarez E, Portela A, Gentilella A, Esteller M. Exploiting tumor vulnerabilities: epigenetics, cancer metabolism and the mTOR pathway in the era of personalized medicine. Cancer Res 2013; 73: 4185-4189.

27 Watt F, Molloy PL. Cytosine methylation prevents binding to DNA of a HeLa cell transcription factor required for optimal expression of the adenovirus major late promoter. Genes Dev 1988; 2: 1136-1143.

$28 \mathrm{Ng} \mathrm{HH}$, Zhang $\mathrm{Y}$, Hendrich B, Johnson CA, Turner BM, Erdjument-Bromage H et al. MBD2 is a transcriptional repressor belonging to the MeCP1 histone deacetylase complex. Nat Genet 1999; 23: 58-61.

29 Selvakumar T, Gjidoda A, Hovde SL, Henry RW. Regulation of human RNA polymerase III transcription by DNMT1 and DNMT3a DNA methyltransferases. J Biol Chem 2012; 287: 7039-7050.

30 Ying H, Kimmelman AC, Lyssiotis CA, Hua S, Chu GC, Fletcher-Sananikone E et al. Oncogenic Kras maintains pancreatic tumors through regulation of anabolic glucose metabolism. Cell 2012; 149: 656-670.

31 Liu W, Li X, Chu ES, Go MY, Xu L, Zhao G et al. Paired box gene 5 is a novel tumor suppressor in hepatocellular carcinoma through interaction with p53 signaling pathway. Hepatology 2011; 53: 843-853.

32 Wang S, Cheng Y, Du W, Lu L, Zhou L, Wang H et al. Zinc-finger protein 545 is a novel tumour suppressor that acts by inhibiting ribosomal RNA transcription in gastric cancer. Gut 2013; 62: 833-841.

33 Yu J, Liang QY, Wang J, Cheng Y, Wang S, Poon TC et al. Zinc-finger protein 331, a novel putative tumor suppressor, suppresses growth and invasiveness of gastric cancer. Oncogene 2013; 32: 307-317.

34 Shen L, Kondo Y, Rosner GL, Xiao L, Hernandez NS, Vilaythong J et al. MGMT promoter methylation and field defect in sporadic colorectal cancer. J Natl Cancer Inst 2005; 97: 1330-1338.

35 Du W, Wang S, Zhou Q, Li X, Chu J, Chang Z et al. ADAMTS9 is a functional tumor suppressor through inhibiting AKT/mTOR pathway and associated with poor survival in gastric cancer. Oncogene 2013; 32: 3319-3328.

36 Choi GC, Li J, Wang Y, Li L, Zhong L, Ma B et al. The metalloprotease ADAMTS8 displays antitumor properties through antagonizing EGFR-MEK- ERK signaling and is silenced in carcinomas by CpG methylation. Mol Cancer Res 2014; 12: 228-238.

37 Patel SA, Graunke DM, Pieper RO. Aberrant silencing of the CpG islandcontaining human O6-methylguanine DNA methyltransferase gene is associated with the loss of nucleosome-like positioning. Mol Cell Biol 1997; 17: 5813-5822.

38 Cunningham JM, Christensen ER, Tester DJ, Kim CY, Roche PC, Burgart LJ et al. Hypermethylation of the hMLH1 promoter in colon cancer with microsatellite instability. Cancer Res 1998; 58: 3455-3460.

39 Robertson KD, Uzvolgyi E, Liang G, Talmadge C, Sumegi J, Gonzales FA et al. The human DNA methyltransferases (DNMTs) 1, 3a and 3b: coordinate mRNA expression in normal tissues and overexpression in tumors. Nucleic Acids Res 1999; 27: 2291-2298.

40 Zhang Y, Reinberg D. Transcription regulation by histone methylation: interplay between different covalent modifications of the core histone tails. Genes Dev 2001; 15: 2343-2360.

41 Greer EL, Shi Y. Histone methylation: a dynamic mark in health, disease and inheritance. Nat Rev Genet 2012; 13: 343-357.
42 Mentch SJ, Mehrmohamadi M, Huang L, Liu X, Gupta D, Mattocks D et al. Histone Methylation Dynamics and Gene Regulation Occur through the Sensing of One-Carbon Metabolism. Cell Metab 2015; 22: 861-873.

43 Mudd SH, Cerone R, Schiaffino MC, Fantasia AR, Minniti G, Caruso U et al. Glycine $\mathrm{N}$-methyltransferase deficiency: a novel inborn error causing persistent isolated hypermethioninaemia. J Inherit Metab Dis 2001; 24: 448-464.

44 Martínez-Chantar ML, Vázquez-Chantada M, Ariz U, Martínez N, Varela M, Luka Z et al. Loss of the glycine $\mathrm{N}$-methyltransferase gene leads to steatosis and hepatocellular carcinoma in mice. Hepatology 2008; 47: 1191-1199.

45 Fuchs BC, Bode BP. Amino acid transporters ASCT2 and LAT1 in cancer: partners in crime? Semin Cancer Biol 2005; 15: 254-266.

46 Haase C, Bergmann R, Fuechtner F, Hoepping A, Pietzsch J. L-type amino acid transporters LAT1 and LAT4 in cancer: uptake of 3-O-methyl-6-18 F-fluoro-Ldopa in human adenocarcinoma and squamous cell carcinoma in vitro and in vivo. J Nucl Med 2007; 48: 2063-2071.

47 Possemato R, Marks KM, Shaul YD, Pacold ME, Kim D, Birsoy K et al. Functional genomics reveal that the serine synthesis pathway is essential in breast cancer. Nature 2011; 476: 346-350.

48 Locasale JW, Grassian AR, Melman T, Lyssiotis CA, Mattaini KR, Bass AJ et al. Phosphoglycerate dehydrogenase diverts glycolytic flux and contributes to oncogenesis. Nat Genet 2011; 43: 869-874.

49 Maddocks OD, Labuschagne CF, Adams PD, Vousden KH. Serine metabolism supports the methionine cycle and DNA/RNA methylation through de novo ATP synthesis in cancer cells. Mol Cell 2016; 61: 210-221.

50 Wu Y, Siadaty MS, Berens ME, Hampton GM, Theodorescu D. Overlapping gene expression profiles of cell migration and tumor invasion in human bladder cancer identify metallothionein $1 \mathrm{E}$ and nicotinamide $\mathrm{N}$-methyltransferase as novel regulators of cell migration. Oncogene 2008; 27: 6679-6689.

51 Zhang J, Wang Y, Li G, Yu H, Xie X. Downregulation of nicotinamide N-methyltransferase induces apoptosis in human breast cancer cells via the mitochondria-mediated pathway. PLoS One 2014; 9: e89202.

52 Thomas MG, Saldanha M, Mistry RJ, Dexter DT, Ramsden DB, Parsons RB et al. Nicotinamide $\mathrm{N}$-methyltransferase expression in SH-SY5Y neuroblastoma and $\mathrm{N} 27$ mesencephalic neurones induces changes in cell morphology via ephrin-B2 and Akt signalling. Cell Death Dis 2013; 4: e669.

53 Tang SW, Yang TC, Lin WC, Chang WH, Wang CC, Lai MK et al. Nicotinamide $\mathrm{N}$-methyltransferase induces cellular invasion through activating matrix metalloproteinase-2 expression in clear cell renal cell carcinoma cells. Carcinogenesis 2011 ; 32: 138-145.

54 Ulanovskaya OA, Zuhl AM, Cravatt BF. NNMT promotes epigenetic remodeling in cancer by creating a metabolic methylation sink. Nat Chem Biol 2013; 9: 300-306.

55 Guo JU, Su Y, Zhong C, Ming GL, Song H. Hydroxylation of 5-methylcytosine by TET1 promotes active DNA demethylation in the adult brain. Cell 2011; 145: 423-434.

56 Tahiliani $M$, Koh KP, Shen $\mathrm{Y}$, Pastor WA, Bandukwala $\mathrm{H}$, Brudno $\mathrm{Y}$ et al. Conversion of 5-methylcytosine to 5-hydroxymethylcytosine in mammalian DNA by MLL partner TET1. Science 2009; 324: 930-935.

57 Ito S, D'Alessio AC, Taranova OV, Hong K, Sowers LC, Zhang Y. Role of Tet proteins in $5 \mathrm{mC}$ to $5 \mathrm{hmC}$ conversion, ES-cell self-renewal and inner cell mass specification. Nature 2010; 466: 1129-1133.

58 Kohli RM, Zhang Y. TET enzymes, TDG and the dynamics of DNA demethylation. Nature 2013; 502: 472-479.

59 Abdel-Wahab O, Mullally A, Hedvat C, Garcia-Manero G, Patel J, Wadleigh M et al. Genetic characterization of TET1, TET2, and TET3 alterations in myeloid malignancies. Blood 2009; 114: 144-147.

60 Gambichler T, Sand M, Skrygan M. Loss of 5-hydroxymethylcytosine and ten-eleven translocation 2 protein expression in malignant melanoma. Melanoma Res 2013; 23: 218-220.

61 Yang H, Liu Y, Bai F, Zhang JY, Ma SH, Liu J et al. Tumor development is associated with decrease of TET gene expression and 5-methylcytosine hydroxylation. Oncogene 2013; 32: 663-669.

62 Kudo Y, Tateishi K, Yamamoto K, Yamamoto S, Asaoka Y, ljichi H et al. Loss of 5-hydroxymethylcytosine is accompanied with malignant cellular transformation. Cancer Sci 2012; 103: 670-676.

63 Kooistra SM, Helin K. Molecular mechanisms and potential functions of histone demethylases. Nat Rev Mol Cell Biol 2012; 13: 297-311.

64 Wu J, Liu S, Liu G, Dombkowski A, Abrams J, Martin-Trevino R et al. Identification and functional analysis of 9p24 amplified genes in human breast cancer. Oncogene 2012; 31: 333-341.

65 Schulte JH, Lim S, Schramm A, Friedrichs N, Koster J, Versteeg R et al. Lysinespecific demethylase 1 is strongly expressed in poorly differentiated neuroblastoma: implications for therapy. Cancer Res 2009; 69: 2065-2071.

66 Xiao M, Yang H, Xu W, Ma S, Lin H, Zhu H et al. Inhibition of alpha-KG-dependent histone and DNA demethylases by fumarate and succinate that are accumulated in mutations of FH and SDH tumor suppressors. Genes Dev 2012; 26: 1326-1338. 
67 Balss J, Meyer J, Mueller W, Korshunov A, Hartmann C, von Deimling A. Analysis of the IDH1 codon 132 mutation in brain tumors. Acta Neuropathol 2008; 116: 597-602.

68 Paschka P, Schlenk RF, Gaidzik VI, Habdank M, Krönke J, Bullinger L et al. IDH1 and IDH2 mutations are frequent genetic alterations in acute myeloid leukemia and confer adverse prognosis in cytogenetically normal acute myeloid leukemia with NPM1 mutation without FLT3 internal tandem duplication. J Clin Oncol 2010; 28: 3636-3643.

69 Ward PS, Patel J, Wise DR, Abdel-Wahab O, Bennett BD, Coller HA et al. The common feature of leukemia-associated IDH1 and IDH2 mutations is a neomorphic enzyme activity converting alpha-ketoglutarate to 2-hydroxyglutarate. Cancer Cell 2010; 17: 225-234.

70 Cairns RA, Iqbal J, Lemonnier F, Kucuk C, de Leval L, Jais JP et al. IDH2 mutations are frequent in angioimmunoblastic T-cell lymphoma. Blood 2012; 119: 1901-1903.

71 Hurley $\mathrm{JH}$, Dean AM, Koshland DE, Stroud RM. Catalytic mechanism of $\mathrm{NADP}(+)$-dependent isocitrate dehydrogenase: implications from the structures of magnesium-isocitrate and NADP+ complexes. Biochemistry 1991; 30: 8671-8678.

72 Dang L, White DW, Gross S, Bennett BD, Bittinger MA, Driggers EM et al. Cancerassociated IDH1 mutations produce 2-hydroxyglutarate. Nature 2009; 462: 739-744

73 Lu C, Ward PS, Kapoor GS, Rohle D, Turcan S, Abdel-Wahab O et al. IDH mutation impairs histone demethylation and results in a block to cell differentiation. Nature 2012; 483: 474-478.

74 Sasaki M, Knobbe CB, Munger JC, Lind EF, Brenner D, Brüstle A et al. IDH1(R132H) mutation increases murine haematopoietic progenitors and alters epigenetics. Nature 2012; 488: 656-659.

75 Terunuma A, Putluri N, Mishra P, Mathé EA, Dorsey TH, Yi M et al. MYC-driven accumulation of 2-hydroxyglutarate is associated with breast cancer prognosis. J Clin Invest 2014; 124: 398-412.

76 Shim EH, Livi CB, Rakheja D, Tan J, Benson D, Parekh V et al. L-2-hydroxyglutarate: an epigenetic modifier and putative oncometabolite in renal cancer. Cancer Discov 2014; 4: 1290-1298.

77 Rzem R, Veiga-da-Cunha M, Noël G, Goffette S, Nassogne MC, Tabarki B et al. A gene encoding a putative FAD-dependent L-2-hydroxyglutarate dehydrogenase is mutated in L-2-hydroxyglutaric aciduria. Proc Natl Acad Sci USAUSA 2004; 101: 16849-16854.

78 Chowdhury R, Yeoh KK, Tian YM, Hillringhaus L, Bagg EA, Rose NR et al. The oncometabolite 2-hydroxyglutarate inhibits histone lysine demethylases. EMBO Rep 2011; 12: 463-469.

79 Xu W, Yang H, Liu Y, Yang Y, Wang P, Kim SH et al. Oncometabolite 2-hydroxyglutarate is a competitive inhibitor of alpha-ketoglutarate-dependent dioxygenases. Cancer Cell 2011; 19: 17-30.

80 Christensen BC, Smith AA, Zheng S, Koestler DC, Houseman EA, Marsit CJ et al. DNA methylation, isocitrate dehydrogenase mutation, and survival in glioma. J Natl Cancer Inst 2011; 103: 143-153.

81 Turcan S, Rohle D, Goenka A, Walsh LA, Fang F, Yilmaz E et al. IDH1 mutation is sufficient to establish the glioma hypermethylator phenotype. Nature 2012; 483: 479-483.

82 Venneti S, Felicella MM, Coyne T, Phillips JJ, Gorovets D, Huse JT et al. Histone 3 lysine 9 trimethylation is differentially associated with isocitrate dehydrogenase mutations in oligodendrogliomas and high-grade astrocytomas. J Neuropathol Exp Neurol 2013; 72: 298-306.

83 Pollard PJ, Wortham NC, Tomlinson IP. The TCA cycle and tumorigenesis: the examples of fumarate hydratase and succinate dehydrogenase. Ann Med 2003; 35: 632-639.

84 Janeway KA, Kim SY, Lodish M, Nosé V, Rustin P, Gaal J et al. Defects in succinate dehydrogenase in gastrointestinal stromal tumors lacking KIT and PDGFRA mutations. Proc Natl Acad Sci USA 2011; 108: 314-318.

85 Ricketts CJ, Shuch B, Vocke CD, Metwalli AR, Bratslavsky G, Middelton L et al. Succinate dehydrogenase kidney cancer: an aggressive example of the Warburg effect in cancer. J Urol 2012; 188: 2063-2071.

86 Hensen EF, Bayley JP. Recent advances in the genetics of SDH-related paraganglioma and pheochromocytoma. Fam Cancer 2011; 10: 355-363.

87 Kantorovich V, King KS, Pacak K. SDH-related pheochromocytoma and paraganglioma. Best Pract Res Clin Endocrinol Metab 2010; 24: 415-424.

88 Hao HX, Khalimonchuk O, Schraders M, Dephoure N, Bayley JP, Kunst H et al. $\mathrm{SDH}$, a gene required for flavination of succinate dehydrogenase, is mutated in paraganglioma. Science 2009; 325: 1139-1142.

89 Letouzé E, Martinelli C, Loriot C, Burnichon N, Abermil N, Ottolenghi C et al. SDH mutations establish a hypermethylator phenotype in paraganglioma. Cancer cell 2013; 23: 739-752.
90 Killian JK, Kim SY, Miettinen M, Smith C, Merino M, Tsokos M et al. Succinate dehydrogenase mutation underlies global epigenomic divergence in gastrointestinal stromal tumor. Cancer Discov 2013; 3: 648-657.

91 Eberharter A, Becker PB. Histone acetylation: a switch between repressive and permissive chromatin. Second in review series on chromatin dynamics. EMBO Rep 2002; 3: 224-229.

92 Nakagawa M, Oda Y, Eguchi T, Aishima S, Yao T, Hosoi F et al. Expression profile of class I histone deacetylases in human cancer tissues. Oncol Rep 2007; 18: 769-774.

93 Weichert W, Röske A, Gekeler V, Beckers T, Stephan C, Jung K et al. Histone deacetylases 1, 2 and 3 are highly expressed in prostate cancer and HDAC2 expression is associated with shorter PSA relapse time after radical prostatectomy. Br J Cancer 2008; 98: 604-610.

94 lyer NG, Ozdag H, Caldas C. p300/CBP and cancer. Oncogene 2004; 23 4225-4231.

95 Gayther SA, Batley SJ, Linger L, Bannister A, Thorpe K, Chin SF et al. Mutations truncating the EP300 acetylase in human cancers. Nat Genet 2000; 24: 300-303.

96 Wang J, Iwasaki H, Krivtsov A, Febbo PG, Thorner AR, Ernst P et al. Conditional MLL-CBP targets GMP and models therapy-related myeloproliferative disease. EMBO J 2005; 24: 368-381.

97 Huntly BJ, Shigematsu H, Deguchi K, Lee BH, Mizuno S, Duclos N et al. MOZ-TIF2, but not $B C R-A B L$, confers properties of leukemic stem cells to committed murine hematopoietic progenitors. Cancer Cell 2004; 6: 587-596.

98 Zaidi N, Swinnen JV, Smans K. ATP-citrate lyase: a key player in cancer metabolism. Cancer Res 2012; 72: 3709-3714.

99 Lee JV, Carrer A, Shah S, Snyder NW, Wei S, Venneti S et al. Akt-dependent metabolic reprogramming regulates tumor cell histone acetylation. Cell Metab 2014; 20: 306-319.

100 Wellen KE, Hatzivassiliou G, Sachdeva UM, Bui TV, Cross JR, Thompson CB. ATP-citrate lyase links cellular metabolism to histone acetylation. Science 2009; 324: 1076-1080.

101 Migita T, Narita T, Nomura K, Miyagi E, Inazuka F, Matsuura M et al. ATP citrate lyase: activation and therapeutic implications in non-small cell lung cancer. Cancer Res 2008; 68: 8547-8554.

102 Knoepfler PS, Zhang XY, Cheng PF, Gafken PR, McMahon SB, Eisenman RN. Myc influences global chromatin structure. EMBO J 2006; 25: 2723-2734.

103 Edmunds LR, Sharma L, Kang A, Lu J, Vockley J, Basu S et al. c-Myc programs fatty acid metabolism and dictates acetyl-CoA abundance and fate. J Biol Chem 2014; 289: 25382-25392

104 Li X, Kazgan N. Mammalian sirtuins and energy metabolism. Int J Biol Sci 2011; 7: 575-587.

105 Fujiki R, Hashiba W, Sekine H, Yokoyama A, Chikanishi T, Ito S et al. GlcNAcylation of histone H2B facilitates its monoubiquitination. Nature 2011; 480: 557-560.

106 Sakabe K, Hart GW. O-GIcNAc transferase regulates mitotic chromatin dynamics. J Biol Chem 2010; 285: 34460-34468.

107 Myers SA, Panning B, Burlingame AL. Polycomb repressive complex 2 is necessary for the normal site-specific O-GICNAc distribution in mouse embryonic stem cells. Proc Natl Acad Sci USA 2011; 108: 9490-9495.

108 Fong JJ, Nguyen BL, Bridger R, Medrano EE, Wells L, Pan S et al. beta-NAcetylglucosamine (O-GlcNAc) is a novel regulator of mitosis-specific phosphorylations on histone H3. J Biol Chem 2012; 287: 12195-12203.

109 Chen Q, Chen Y, Bian C, Fujiki R, Yu X. TET2 promotes histone O-GlcNAcylation during gene transcription. Nature 2013; 493: 561-564.

110 Ito R, Katsura S, Shimada H, Tsuchiya H, Hada M, Okumura T et al. TET3-OGT interaction increases the stability and the presence of OGT in chromatin. Genes Cells 2014; 19: 52-65.

111 Chu CS, Lo PW, Yeh YH, Hsu PH, Peng SH, Teng YC et al. O-GlcNAcylation regulates EZH2 protein stability and function. Proc Natl Acad Sci USA 2014; 111: 1355-1360.

112 Ranuncolo SM, Ghosh S, Hanover JA, Hart GW, Lewis BA. Evidence of the involvement of O-GICNAc-modified human RNA polymerase II CTD in transcription in vitro and in vivo. J Biol Chem 2012; 287: 23549-23561.

113 Pinho SS, Reis CA. Glycosylation in cancer: mechanisms and clinical implications. Nat Rev Cancer 2015; 15: 540-555.

114 Caldwell SA, Jackson SR, Shahriari KS, Lynch TP, Sethi G, Walker S et al. Nutrient sensor O-GICNAc transferase regulates breast cancer tumorigenesis through targeting of the oncogenic transcription factor FoxM1. Oncogene 2010; 29: 2831-2842.

115 Lucena MC, Carvalho-Cruz P, Donadio JL, Oliveira IA, de Queiroz RM, MarinhoCarvalho MM et al. Epithelial Mesenchymal Transition Induces Aberrant Glycosylation through Hexosamine Biosynthetic Pathway Activation. J Biol Chem 2016; 291: 12917-12929.

116 Onodera Y, Nam JM, Bissell MJ. Increased sugar uptake promotes oncogenesis via EPAC/RAP1 and O-GICNAc pathways. J Clin Invest 2014; 124: 367-384. 
117 Itkonen HM, Minner S, Guldvik IJ, Sandmann MJ, Tsourlakis MC, Berge V et al. O-GlcNAc transferase integrates metabolic pathways to regulate the stability of c-MYC in human prostate cancer cells. Cancer Res 2013; 73: 5277-5287.

118 Wellen KE, Lu C, Mancuso A, Lemons JM, Ryczko M, Dennis JW et al. The hexosamine biosynthetic pathway couples growth factor-induced glutamine uptake to glucose metabolism. Genes Dev 2010; 24: 2784-2799.

119 Guillaumond F, Leca J, Olivares O, Lavaut MN, Vidal N, Berthezène $\mathrm{P}$ et al. Strengthened glycolysis under hypoxia supports tumor symbiosis and hexosamine biosynthesis in pancreatic adenocarcinoma. Proc Natl Acad Sci USA 2013; 110: 3919-3924.

120 Liu X, Wang X, Zhang J, Lam EK, Shin VY, Cheng AS et al. Warburg effect revisited: an epigenetic link between glycolysis and gastric carcinogenesis. Oncogene 2010; 29: 442-450.

121 Chen M, Zhang J, Li N, Qian Z, Zhu M, Li Q et al. Promoter hypermethylation mediated downregulation of FBP1 in human hepatocellular carcinoma and colon cancer. PLoS One 2011; 6: e25564.

122 Dong C, Yuan T, Wu Y, Wang Y, Fan TW, Miriyala S et al. Loss of FBP1 by Snailmediated repression provides metabolic advantages in basal-like breast cancer. Cancer Cell 2013; 23: 316-331.

123 Li H, Wang J, Xu H, Xing R, Pan Y, Li W et al. Decreased fructose-1,6-bisphosphatase-2 expression promotes glycolysis and growth in gastric cancer cells. Mol Cancer 2013; 12: 110.

124 Lopez-Serra P, Marcilla M, Villanueva A, Ramos-Fernandez A, Palau A, Leal L et al. A DERL3-associated defect in the degradation of SLC2A1 mediates the Warburg effect. Nat Commun 2014; 5: 3608.

125 Desai $S$, Ding M, Wang B, Lu Z, Zhao Q, Shaw K et al. Tissue-specific isoform switch and DNA hypomethylation of the pyruvate kinase PKM gene in human cancers. Oncotarget 2014; 5: 8202-8210.

126 Kang YH, Lee HS, Kim WH. Promoter methylation and silencing of PTEN in gastric carcinoma. Lab Invest 2002; 82: 285-291.

127 Salvesen HB, MacDonald N, Ryan A, Jacobs IJ, Lynch ED, Akslen LA et al. PTEN methylation is associated with advanced stage and microsatellite instability in endometrial carcinoma. Int J Cancer 2001; 91: 22-26.

128 Soria JC, Lee HY, Lee Jl, Wang L, Issa JP, Kemp BL et al. Lack of PTEN expression in non-small cell lung cancer could be related to promoter methylation. Clin Cancer Res 2002; 8: 1178-1184.

129 García JM, Silva J, Peña C, Garcia V, Rodríguez R, Cruz MA et al. Promoter methylation of the PTEN gene is a common molecular change in breast cancer. Genes Chromosomes Cancer 2004; 41: 117-124.

130 Alvarez-Nuñez F, Bussaglia E, Mauricio D, Ybarra J, Vilar M, Lerma E et al. PTEN promoter methylation in sporadic thyroid carcinomas. Thyroid 2006; 16: 17-23.

131 Trojan J, Brieger A, Raedle J, Esteller M, Zeuzem S. 5'-CpG island methylation of the LKB1/STK11 promoter and allelic loss at chromosome 19p13.3 in sporadic colorectal cancer. Gut 2000; 47: 272-276.

132 Esteller M, Avizienyte E, Corn PG, Lothe RA, Baylin SB, Aaltonen LA et al. Epigenetic inactivation of LKB1 in primary tumors associated with the PeutzJeghers syndrome. Oncogene 2000; 19: 164-168.

133 Vanharanta S, Shu W, Brenet F, Hakimi AA, Heguy A, Viale A et al. Epigenetic expansion of VHL-HIF signal output drives multiorgan metastasis in renal cancer. Nat Med 2013; 19: 50-56.

134 Herman JG, Latif F, Weng Y, Lerman MI, Zbar B, Liu S et al. Silencing of the VHL tumor-suppressor gene by DNA methylation in renal carcinoma. Proc Natl Acad Sci USA 1994; 91: 9700-9704.

135 Schmitt AM, Schmid S, Rudolph T, Anlauf M, Prinz C, Klöppel G et al. VHL inactivation is an important pathway for the development of malignant sporadic pancreatic endocrine tumors. Endocr Relat Cancer 2009; 16: 1219-1227.

136 Hatzimichael E, Dasoula A, Shah R, Syed N, Papoudou-Bai A, Coley HM et al. The prolyl-hydroxylase EGLN3 and not EGLN1 is inactivated by methylation in plasma cell neoplasia. Eur J Haematol 2010; 84: 47-51.

137 Rawluszko AA, Bujnicka KE, Horbacka K, Krokowicz P, Jagodzinski PP. Expression and DNA methylation levels of prolyl hydroxylases PHD1, PHD2, PHD3 and asparaginyl hydroxylase FIH in colorectal cancer. BMC Cancer 2013; 13: 526.

138 Place TL, Fitzgerald MP, Venkataraman S, Vorrink SU, Case AJ, Teoh ML et al. Aberrant promoter CpG methylation is a mechanism for impaired PHD3 expression in a diverse set of malignant cells. PLOS ONE 2011; 6: e14617.

139 Xiao C, Kim HS, Lahusen T, Wang RH, Xu X, Gavrilova O et al. SIRT6 deficiency results in severe hypoglycemia by enhancing both basal and insulin-stimulated glucose uptake in mice. J Biol Chem 2010; 285: 36776-36784.

140 Zhong L, D'Urso A, Toiber D, Sebastian C, Henry RE, Vadysirisack DD et al. The histone deacetylase Sirt6 regulates glucose homeostasis via Hif1alpha. Cell 2010; 140: 280-293.

141 Zhong L, Mostoslavsky R. SIRT6: a master epigenetic gatekeeper of glucose metabolism. Transcription 2010; 1: 17-21.
142 Sebastián C, Zwaans BM, Silberman DM, Gymrek M, Goren A, Zhong L et al. The histone deacetylase SIRT6 is a tumor suppressor that controls cancer metabolism. Cell 2012; 151: 1185-1199.

143 Zhang ZG, Qin CY. Sirt6 suppresses hepatocellular carcinoma cell growth via inhibiting the extracellular signalregulated kinase signaling pathway. Mol Med Rep 2014; 9: 882-888.

144 Shin J, He M, Liu Y, Paredes S, Villanova L, Brown K et al. SIRT7 represses Myc activity to suppress ER stress and prevent fatty liver disease. Cell Rep 2013; 5: 654-665.

145 Barber MF, Michishita-Kioi E, Xi Y, Tasselli L, Kioi M, Moqtaderi Z et al. SIRT7 links H3K18 deacetylation to maintenance of oncogenic transformation. Nature 2012; 487: 114-118.

146 Liu PY, Xu N, Malyukova A, Scarlett CJ, Sun YT, Zhang XD et al. The histone deacetylase SIRT2 stabilizes Myc oncoproteins. Cell Death Differ 2013; 20: 503-514.

147 Yamasaki T, Seki N, Yoshino $\mathrm{H}$, Itesako T, Yamada $\mathrm{Y}$, Tatarano $\mathrm{S}$ et al. Tumorsuppressive microRNA-1291 directly regulates glucose transporter 1 in renal cell carcinoma. Cancer Sci 2013; 104: 1411-1419.

148 Fei X, Qi M, Wu B, Song Y, Wang Y, Li T et al. MicroRNA-195-5p suppresses glucose uptake and proliferation of human bladder cancer T24 cells by regulating GLUT3 expression. FEBS Lett 2012; 586: 392-397.

149 Dai DW, Lu Q, Wang LX, Zhao WY, Cao YQ, Li YN et al. Decreased miR-106a inhibits glioma cell glucose uptake and proliferation by targeting SLC2A3 in GBM. BMC cancer 2013; 13: 478.

150 Chen YH, Heneidi S, Lee JM, Layman LC, Stepp DW, Gamboa GM et al. miRNA-93 inhibits GLUT4 and is overexpressed in adipose tissue of polycystic ovary syndrome patients and women with insulin resistance. Diabetes 2013; 62: 2278-2286.

151 Peschiaroli A, Giacobbe A, Formosa A, Markert EK, Bongiorno-Borbone L, Levine AJ et al. miR-143 regulates hexokinase 2 expression in cancer cells. Oncogene 2013; 32: 797-802.

152 Fang R, Xiao T, Fang Z, Sun Y, Li F, Gao Y et al. MicroRNA-143 (miR-143) regulates cancer glycolysis via targeting hexokinase 2 gene. J Biol Chem 2012; 287: 23227-23235.

153 Jiang S, Zhang LF, Zhang HW, Hu S, Lu MH, Liang S et al. A novel miR-155/ miR-143 cascade controls glycolysis by regulating hexokinase 2 in breast cancer cells. EMBO J 2012; 31: 1985-1998.

154 Gregersen LH, Jacobsen A, Frankel LB, Wen J, Krogh A, Lund AH et al. MicroRNA-143 down-regulates Hexokinase 2 in colon cancer cells. BMC cancer 2012; 12: 232.

155 Zhao S, Liu H, Liu Y, Wu J, Wang C, Hou X et al. miR-143 inhibits glycolysis and depletes stemness of glioblastoma stem-like cells. Cancer Lett 2013; 333: 253-260.

156 Yoshino $\mathrm{H}$, Enokida $\mathrm{H}$, Itesako $\mathrm{T}$, Kojima $\mathrm{S}$, Kinoshita $\mathrm{T}$, Tatarano $\mathrm{S}$ et al. Tumor-suppressive microRNA-143/145 cluster targets hexokinase-2 in renal cell carcinoma. Cancer Sci 2013; 104: 1567-1574.

157 Ahmad A, Aboukameel A, Kong D, Wang Z, Sethi S, Chen W et al. Phosphoglucose isomerase/autocrine motility factor mediates epithelialmesenchymal transition regulated by miR-200 in breast cancer cells. Cancer Res 2011; 71: 3400-3409.

158 Castoldi M, Vujic Spasic M, Altamura S, Elmén J, Lindow M, Kiss J et al. The liverspecific microRNA miR-122 controls systemic iron homeostasis in mice. J Clin Invest 2011; 121: 1386-1396.

159 Kefas B, Comeau L, Erdle N, Montgomery E, Amos S, Purow B. Pyruvate kinase M2 is a target of the tumor-suppressive microRNA-326 and regulates the survival of glioma cells. Neuro Oncol 2010; 12: 1102-1112.

160 Wong TS, Liu XB, Ho CW, Yuen PW, Ng WM, Wei IW. Identification of pyruvate kinase type $M 2$ as potential oncoprotein in squamous cell carcinoma of tongue through microRNA profiling. Int J Cancer 2008; 123: 251-257.

161 Rathore MG, Saumet A, Rossi JF, de Bettignies C, Tempé D, Lecellier CH et al. The NF-kappaB member p65 controls glutamine metabolism through miR-23a. Int J Biochem Cell Biol 2012; 44: 1448-1456.

162 Chan SY, Zhang YY, Hemann C, Mahoney CE, Zweier JL, Loscalzo J. MicroRNA-210 controls mitochondrial metabolism during hypoxia by repressing the iron-sulfur cluster assembly proteins ISCU1/2. Cell Metab 2009; 10: 273-284.

163 Cluntun AA, Huang H, Dai L, Liu X, Zhao Y, Locasale JW. The rate of glycolysis quantitatively mediates specific histone acetylation sites. Cancer Metab 2015; 3: 10 .

164 Liu XS, Little JB, Yuan ZM. Glycolytic metabolism influences global chromatin structure. Oncotarget 2015; 6: 4214-4225.

165 Chen W, Gueron M. The inhibition of bovine heart hexokinase by 2-deoxyD-glucose-6-phosphate: characterization by 31 P NMR and metabolic implications. Biochimie 1992; 74: 867-873. 
166 Moussaieff A, Rouleau M, Kitsberg D, Cohen M, Levy G, Barasch D et al. Glycolysis-mediated changes in acetyl-CoA and histone acetylation control the early differentiation of embryonic stem cells. Cell Metab 2015; 21: 392-402.

167 Robinson MM, McBryant SJ, Tsukamoto T, Rojas C, Ferraris DV, Hamilton SK et al. Novel mechanism of inhibition of rat kidney-type glutaminase by bis-2(5-phenylacetamido-1,2,4-thiadiazol-2-yl)ethyl sulfide (BPTES). Biochem J 2007; 406: 407-414.

168 Wang JB, Erickson JW, Fuji R, Ramachandran S, Gao P, Dinavahi R et al. Targeting mitochondrial glutaminase activity inhibits oncogenic transformation. Cancer Cell 2010; 18: 207-219.

169 Simpson NE, Tryndyak VP, Pogribna M, Beland FA, Pogribny IP. Modifying metabolically sensitive histone marks by inhibiting glutamine metabolism affects gene expression and alter cancer cell phenotype. Epigenetics 2012; 7: 1413-1420.

170 Simpson NE, Tryndyak VP, Beland FA, Pogribny IP. An in vitro investigation of metabolically sensitive biomarkers in breast cancer progression. Breast Cancer Res Treat 2012; 133: 959-968.

171 Elhammali A, Ippolito JE, Collins L, Crowley J, Marasa J, Piwnica-Worms D. A highthroughput fluorimetric assay for 2-hydroxyglutarate identifies Zaprinast as a glutaminase inhibitor. Cancer Discov 2014; 4: 828-839.

172 Rohle D1, Popovici-Muller J, Palaskas N, Turcan S, Grommes C, Campos C et al. An inhibitor of mutant IDH1 delays growth and promotes differentiation of glioma cells. Science 2013; 340: 626-630.

173 Li L, Paz AC, Wilky BA, Johnson B, Galoian K, Rosenberg A et al. Treatment with a small molecule mutant IDH1 inhibitor suppresses tumorigenic activity and decreases production of the oncometabolite 2-hydroxyglutarate in human chondrosarcoma cells. PLoS One 2015; 10: e0133813.

174 Davis Ml, Gross S, Shen M, Straley KS, Pragani R, Lea WA et al. Biochemical, cellular, and biophysical characterization of a potent inhibitor of mutant isocitrate dehydrogenase IDH1. J Biol Chem 2014; 289: 13717-13725.

$175 \mathrm{Kim} \mathrm{HJ}$, Choi BY, Keum YS. Identification of a new selective chemical inhibitor of mutant isocitrate dehydrogenase-1. J Cancer Prev 2015; 20: 78-83.

176 Deng G, Shen J, Yin M, McManus J, Mathieu M, Gee P et al. Selective inhibition of mutant isocitrate dehydrogenase 1 (IDH1) via disruption of a metal binding network by an allosteric small molecule. J Biol Chem 2015; 290: 762-774.

177 Zheng B, Yao Y, Liu Z, Deng L, Anglin JL, Jiang H et al. Crystallographic investigation and selective inhibition of mutant isocitrate dehydrogenase. ACS Med Chem Lett 2013; 4: 542-546.

178 Okoye-Okafor UC, Bartholdy B, Cartier J, Gao EN, Pietrak B, Rendina AR et al. New IDH1 mutant inhibitors for treatment of acute myeloid leukemia. Nat Chem Biol 2015; 11: 878-886.

179 Shih AH, Shank KR, Meydan C, Intlekofer AM, Ward P, Thompson CB et al. AG-221, a small molecule mutant IDH2 inhibitor, remodels epigenetic state of IDH2-mutant cells and induces alterations in self-renewal/differentiation in IDH2mutant AML model in vivo. Blood 2014; 124: 237.

180 Ellwood-Yen K, Wang F, Travins J, Chen Y, Yang H, Straley K et al. AG-221 offers a survival advantage in a primary human IDH2 mutant AML xenograft model. Cancer Res 2014; 74(Suppl): 3116

181 Yen K, Wang F, Travins J, Chen Y, Yang H, Straley K et al. AG-221 offers a survival advantage in a primary human IDH2 mutant AML xenograft model. Blood 2013; 122: 240.

182 DiNardo C, Stein EM, Altman JK, Collins R, DeAngelo DJ, Fathi AT et al. Ag-221, an oral, selective, first-in-class, potent inhibitor of the IDH2 mutant enzyme, induced durable responses in a phase 1 study of IDH2 mutation-positive advanced hematologic malignancies. Haematologica 2015; 100: 216-217.

183 Wang F, Travins J, DeLaBarre B, Penard-Lacronique V, Schalm S, Hansen E et al. Targeted inhibition of mutant IDH2 in leukemia cells induces cellular differentiation. Science 2013; 340: 622-626.

184 Kernytsky A, Wang F, Hansen E, Schalm S, Straley K, Gliser C et al. IDH2 mutationinduced histone and DNA hypermethylation is progressively reversed by smallmolecule inhibition. Blood 2015; 125: 296-303.

185 Glazer RI, Hartman KD, Knode MC, Richard MM, Chiang PK, Tseng CK et al. 3-Deazaneplanocin: a new and potent inhibitor of S-adenosylhomocysteine hydrolase and its effects on human promyelocytic leukemia cell line HL-60. Biochem Biophys Res Commun 1986; 135: 688-694.

186 Miranda TB, Cortez CC, Yoo CB, Liang G, Abe M, Kelly TK et al. DZNep is a global histone methylation inhibitor that reactivates developmental genes not silenced by DNA methylation. Mol Cancer Ther 2009; 8: 1579-1588.

187 Momparler RL, Cote S, Momparler LF, Idaghdour Y. Epigenetic therapy of acute myeloid leukemia using 5-aza-2'-deoxycytidine (decitabine) in combination with inhibitors of histone methylation and deacetylation. Clin Epigenet 2014; 6: 19.

188 Momparler RL, Idaghdour Y, Marquez VE, Momparler LF. Synergistic antileukemic action of a combination of inhibitors of DNA methylation and histone methylation. Leuk Res 2012; 36: 1049-1054.
189 Jiang X, Tan J, Li J, Kivimäe S, Yang X, Zhuang L et al. DACT3 is an epigenetic regulator of Wnt/beta-catenin signaling in colorectal cancer and is a therapeutic target of histone modifications. Cancer Cell 2008; 13: 529-541.

190 Momparler RL, Cote S. Targeting of cancer stem cells by inhibitors of DNA and histone methylation. Expert Opin Investig Drugs 2015; 24: 1031-1043.

191 Kraus D, Yang Q, Kong D, Banks AS, Zhang L, Rodgers JT et al. Nicotinamide $\mathrm{N}$-methyltransferase knockdown protects against diet-induced obesity. Nature 2014; 508: 258-262.

192 Dehennaut V, Lefebvre T, Sellier C, Leroy Y, Gross B, Walker S et al. O-linked $\mathrm{N}$-acetylglucosaminyltransferase inhibition prevents G2/M transition in Xenopus laevis oocytes. J Biol Chem 2007; 282: 12527-12536.

193 Olivier-Van Stichelen S, Guinez C, Mir AM, Perez-Cervera Y, Liu C, Michalski JC et al. The hexosamine biosynthetic pathway and O-GlcNAcylation drive the expression of beta-catenin and cell proliferation. Am J Physiol Endocrinol Metab 2012; 302: E417-E424.

194 Zhou F, Huo J, Liu Y, Liu H, Liu G, Chen Y et al. Elevated glucose levels impair the WNT/beta-catenin pathway via the activation of the hexosamine biosynthesis pathway in endometrial cancer. J Steroid Biochem Mol Biol 2016; 159: 19-25.

195 Olivier-Van Stichelen S, Dehennaut V, Buzy A, Zachayus JL, Guinez C, Mir AM et al. O-GlcNAcylation stabilizes beta-catenin through direct competition with phosphorylation at threonine 41. FASEB J 2014; 28: 3325-3338.

196 Lin SH, Liu T, Ming X, Tang Z, Fu L, Schmitt-Kopplin P et al. Regulatory role of hexosamine biosynthetic pathway on hepatic cancer stem cell marker CD133 under low glucose conditions. Sci Rep 2016; 6: 21184.

197 Rodriguez-Paredes M, Esteller M. A combined epigenetic therapy equals the efficacy of conventional chemotherapy in refractory advanced non-small cell lung cancer. Cancer Discov 2011; 1: 557-559.

198 Borodovsky A, Salmasi V, Turcan S, Fabius AW, Baia GS, Eberhart CG et al. 5 -azacytidine reduces methylation, promotes differentiation and induces tumor regression in a patient-derived IDH1 mutant glioma xenograft. Oncotarget 2013; 4: 1737-1747.

199 Turcan S, Fabius AW, Borodovsky A, Pedraza A, Brennan C, Huse J et al. Efficient induction of differentiation and growth inhibition in IDH1 mutant glioma cells by the DNMT inhibitor decitabine. Oncotarget 2013; 4: 1729-1736.

200 Alcarraz-Vizan G, Boren J, Lee WN, Cascante M. Histone deacetylase inhibition results in a common metabolic profile associated with HT29 differentiation. Metabolomics 2010; 6: 229-237.

201 Wardell SE, Ilkayeva OR, Wieman HL, Frigo DE, Rathmell JC, Newgard CB et al. Glucose metabolism as a target of histone deacetylase inhibitors. Mol Endocrinol 2009; 23: 388-401.

202 Amoêdo ND, Rodrigues MF, Pezzuto P, Galina A, da Costa RM, de Almeida FC et al. Energy metabolism in $\mathrm{H} 460$ lung cancer cells: effects of histone deacetylase inhibitors. PLoS One 2011; 6: e22264.

203 Rodrigues MF, Carvalho E, Pezzuto P, Rumjanek FD, Amoedo ND. Reciprocal modulation of histone deacetylase inhibitors sodium butyrate and trichostatin A on the energy metabolism of breast cancer cells. J Cell Biochem 2015; 116: 797-808.

204 Feldman JL, Baeza J, Denu JM. Activation of the protein deacetylase SIRT6 by long-chain fatty acids and widespread deacylation by mammalian sirtuins. J Biol Chem 2013; 288: 31350-31356.

205 Villalba JM, Alcain FJ. Sirtuin activators and inhibitors. BioFactors 2012; 38: 349-359.

206 Bader AG, Brown D, Winkler M. The promise of microRNA replacement therapy. Cancer Res 2010; 70: 7027-7030.

207 Ebert MS, Sharp PA. MicroRNA sponges: progress and possibilities. RNA 2010; 16: 2043-2050.

208 Li Z, Rana TM. Therapeutic targeting of microRNAs: current status and future challenges. Nat Rev Drug Discov 2014; 13: 622-638.

209 Meng F, Henson R, Wehbe-Janek H, Ghoshal K, Jacob ST, Patel T. MicroRNA-21 regulates expression of the PTEN tumor suppressor gene in human hepatocellular cancer. Gastroenterology 2007; 133: 647-658.

210 Pereira DM, Rodrigues PM, Borralho PM, Rodrigues CM. Delivering the promise of miRNA cancer therapeutics. Drug Discov Today 2013; 18: 282-289.

211 Braiteh F, Soriano AO, Garcia-Manero G, Hong D, Johnson MM, Silva Lde P et al. Phase I study of epigenetic modulation with 5 -azacytidine and valproic acid in patients with advanced cancers. Clin Cancer Res 2008; 14: 6296-6301.

212 Juergens RA, Wrangle J, Vendetti FP, Murphy SC, Zhao M, Coleman B et al. Combination epigenetic therapy has efficacy in patients with refractory advanced non-small cell lung cancer. Cancer Discov 2011; 1: 598-607.

213 Chu BF, Karpenko MJ, Liu Z, Aimiuwu J, Villalona-Calero MA, Chan KK et al. Phase I study of 5-aza-2'-deoxycytidine in combination with valproic acid in non-smallcell lung cancer. Cancer Chemother Pharmacol 2013; 71: 115-121.

214 Brown JM, Giaccia AJ. The unique physiology of solid tumors: opportunities (and problems) for cancer therapy. Cancer Res 1998; 58: 1408-1416. 
215 Wilson WR, Hay MP. Targeting hypoxia in cancer therapy. Nat Rev Cancer 2011; 11: 393-410.

216 Johnson AB, Denko N, Barton MC. Hypoxia induces a novel signature of chromatin modifications and global repression of transcription. Mutat Res 2008; 640: 174-179.

217 Skowronski K, Dubey S, Rodenhiser D, Coomber B. Ischemia dysregulates DNA methyltransferases and p16INK4a methylation in human colorectal cancer cells. Epigenetics 2010; 5: 547-556.

218 Liu Q, Liu L, Zhao Y, Zhang J, Wang D, Chen J et al. Hypoxia induces genomic DNA demethylation through the activation of HIF-1a and transcriptional upregulation of MAT2A in hepatoma cells. Mol Cancer Ther 2011; 10: 1113-1123.

219 Mariani CJ, Vasanthakumar A, Madzo J, Yesilkanal A, Bhagat T, Yu Y et al. TET1-mediated hydroxymethylation facilitates hypoxic gene induction in neuroblastoma. Cell Rep 2014; 7: 1343-1352.

220 Hattori M, Yokoyama Y, Hattori T, Motegi S, Amano H, Hatada I et al. Global DNA hypomethylation and hypoxia-induced expression of the ten eleven translocation (TET) family, TET1, in scleroderma fibroblasts. Exp Dermatol 2015; 24: $841-846$.

221 Lee SH, Kim J, Kim WH, Lee YM. Hypoxic silencing of tumor suppressor RUNX3 by histone modification in gastric cancer cells. Oncogene 2009; 28: 184-194.

222 Daud Al, Dawson J, DeConti RC, Bicaku E, Marchion D, Bastien S et al. Potentiation of a topoisomerase I inhibitor, karenitecin, by the histone deacetylase inhibitor valproic acid in melanoma: translational and phase I/II clinical trial. Clin Cancer Res 2009; 15: 2479-2487.
223 Ramalingam SS, Maitland ML, Frankel P, Argiris AE, Koczywas M, Gitlitz B et al. Carboplatin and Paclitaxel in combination with either vorinostat or placebo for first-line therapy of advanced non-small-cell lung cancer. J Clin Oncol 2010; 28: 56-62.

224 Munster PN, Thurn KT, Thomas S, Raha P, Lacevic M, Miller A et al. A phase II study of the histone deacetylase inhibitor vorinostat combined with tamoxifen for the treatment of patients with hormone therapy-resistant breast cancer. Br J Cancer 2011; 104: 1828-1835.

225 Witta SE, Jotte RM, Konduri K, Neubauer MA, Spira Al, Ruxer RL et al. Randomized phase II trial of erlotinib with and without entinostat in patients with advanced non-small-cell lung cancer who progressed on prior chemotherapy. $J$ Clin Oncol 2012; 30: 2248-2255.

This work is licensed under a Creative Commons Attribution 4.0 International License. The images or other third party material in this article are included in the article's Creative Commons license, unless indicated otherwise in the credit line; if the material is not included under the Creative Commons license, users will need to obtain permission from the license holder to reproduce the material. To view a copy of this license, visit http://creativecommons.org/licenses/ by/4.0/

(c) The Author(s) 2017 